\title{
Autoignition Characteristics of Oxygenated Gasolines
}

\author{
Changyoul Lee ${ }^{1 \#}$, Ahfaz Ahmed ${ }^{2 \#}$, Ehson F. Nasir ${ }^{2}$ Jihad Badra $^{3}$, Gautam Kalghatgi ${ }^{3}$, S. \\ Mani Sarathy ${ }^{2}$, Henry Curran ${ }^{1}$, Aamir Farooq ${ }^{2 *}$ \\ ${ }^{1}$ Combustion Chemistry Center, National University of Ireland Galway, Ireland \\ ${ }^{2}$ King Abdullah University of Science and Technology (KAUST), Clean Combustion Research \\ Center, Physical Sciences and Engineering Division, Thuwal, Saudi Arabia \\ ${ }^{3}$ Fuel Technology Center, Research and Development Center, Saudi Aramco, Dhahran, Saudi Arabia \\ *corresponding author email: aamir.farooq@kaust.edu.sa \\ \#These two authors made equal contribution to the paper.
}

\begin{abstract}
Gasoline anti-knock quality, defined by the research and motor octane numbers (RON and MON), is important for increasing spark ignition (SI) engine efficiency. Gasoline knock resistance can be increased using a number of blending components. For over two decades, ethanol has become a popular anti-knock blending agent with gasoline fuels due to its production from bio-derived resources. This work explores the oxidation behavior of two oxygenated certification gasoline fuels and the variation of fuel reactivity with molecular composition. Ignition delay times of Haltermann $(\mathrm{RON}=91)$ and Coryton $(\mathrm{RON}=97.5)$ gasolines have been measured in a high-pressure shock tube and in a rapid compression machine at three pressures of 10, 20 and 40 bar, at equivalence ratios of $\varphi=0.45,0.9$ and 1.8, and in the temperature range of $650-1250 \mathrm{~K}$. The results indicate that the effects of fuel octane number and fuel composition on ignition characteristics are strongest in the intermediate temperature (negative temperature coefficient) region. To simulate the reactivity of these gasolines, three kinds of surrogates, consisting of three, four and eight components, are proposed and compared with the gasoline ignition delay times. It is shown that more complex surrogate mixtures are needed to emulate the reactivity of gasoline with higher octane sensitivity $(\mathrm{S}=\mathrm{RON}-\mathrm{MON})$. Detailed kinetic analyses are performed to illustrate the dependence of gasoline ignition delay times on fuel composition and, in particular, on ethanol content.
\end{abstract}




\section{Introduction}

Many advanced combustion engine technologies have been proposed in recent years to achieve higher efficiencies and lower emissions. Most of these technologies revolve around low-temperature combustion (LTC) concepts and include variants such as homogeneous charge compression ignition (HCCI), partially premixed combustion (PPC) and reactivity controlled compression ignition (RCCI) [1-3]. New combustion modes used for advanced combustion engines are mainly controlled by the autoignition of fuel/air mixture. Therefore, fundamental understanding of the chemical kinetics of fuel combustion is essential in the development and optimization of these new engine technologies [4].

Gasolines, one of the most widely used light duty automotive fuels, are complex mixtures containing hundreds of different chemical compounds such as alkanes, aromatics, naphthenes and olefins. Thus, to develop a detailed reaction mechanism comprising all of the components present in gasoline in order to predict gasoline ignition behavior is intractable. Owing to this complexity, a popular approach to describe the combustion behavior of gasoline is to use a surrogate fuel composed of several reference components. Various gasoline surrogates, ranging from single to multi-components, have been proposed in the literature [58]. The primary reference fuels (PRFs), which are binary blends of $n$-heptane and iso-octane, are widely adopted, given their relatively well-validated chemistry. However, previous studies have shown that PRFs may not be suitable surrogates over wide range of engine operating conditions [8-11]. The physical and chemical properties of PRFs are different from those of real gasoline fuels because they not only contain alkanes and iso-alkanes but also cycloalkanes, aromatics, alkenes and oxygenates [9-12]. Several recent studies have instead proposed a ternary mixture of PRF/toluene (also known as toluene primary reference fuels, TPRFs) as gasoline surrogates [13-15]. By adding toluene to PRFs, TPRFs possess gasoline's inherent fuel sensitivity and have gone some way in assisting the development of simple gasoline surrogate models which capture important combustion metrics $[16,17]$ such as ignition delay time and flame speed. With the availability of complex reaction mechanisms for many different alkenes [18] and cycloalkanes [19], four- and five- component surrogates containing 1-hexene and 1-pentene representing alkenes and methylcyclohexane representing cycloalkanes, respectively, have also been proposed [20-22]. Recently, Sarathy et al. [23] and Ahmed et al. [24] proposed multi-component surrogates to reproduce the low-temperature auto-ignition behavior of transportation gasoline fuels. In addition to various hydrocarbon classes present in gasoline fuels, the employment of oxygenated fuels such as ethanol in liquid transportation fuels has grown significantly in recent years. In various countries across the world such as Germany, France, Finland and in the U.S., ethanol is used as a blend of $10 \%$ by volume (E10) and the ethanol content in blends is anticipated to increase into the future [25]. The key drivers for this positive prospect of oxygenate usage are $\mathrm{CO}_{2}$-emission legislation and the target of biofuel share in the transportation sector [26].

Fundamental combustion experimental studies on fully blended gasoline fuels are quite scarce. A few studies have focused on measuring their auto-ignition behavior in shock tubes and rapid compression machines. The work of Gauthier et al. [27] on the autoignition of full-blend, non-oxygenated, research grade gasoline (RD 387) in a shock tube has been 
extensively used to validate various surrogate models reported in the literature [28-30]. The shock tube experiments were conducted over relatively high temperatures of $850-1280 \mathrm{~K}$, at pressures in the range $15-60$ atm and at varying equivalence ratios of $\varphi=0.5,1.0$, and 2.0. To study the auto-ignition of gasoline at low temperatures, Kukkadapu et al. [31] measured ignition delay data of RD 387 using an RCM in the temperature range $640-955 \mathrm{~K}$, at compressed gas pressures of 20 and 40 bar for equivalence ratios ranging from 0.3 to 1.0. In ref. [32], the ignition delay data were simulated using a quaternary gasoline surrogate model developed by Mehl et al. [33], consisting of 57\% iso-octane, 16\% n-heptane, 23\% toluene and 4\% 2-pentene (by volume). Recently, Kukkadapu et al. [34] studied the autoignition characteristics of two gasoline surrogates, suggested by Mehl et al. [35] and Gauthier et al. [36], using an RCM at elevated pressure and low temperature conditions with lean fuel/air mixtures. Sarathy et al. [37] investigated the ignition characteristics of two non-oxygenated alkane-rich FACE (Fuels for Advanced Combustion Engines) gasoline fuels and their corresponding PRF blend in a shock tube and a rapid compression machine and proposed multicomponent surrogates containing iso-pentane, 2-methylhexane, iso-octane, $n$-butane, $n$ heptane and toluene. In another recent study, Sarathy et al. [36] examined the ignition behavior of two high-sensitivity FACE gasoline fuels and demonstrated the superior performance of multi-component surrogates over binary and ternary ones. To the authors' knowledge, detailed autoignition study of full-blend gasoline containing oxygenates such as ethanol is not available in the literature. The octane number variation due to the addition of ethanol to gasoline fuel surrogates such as PRF and TPRF have recently been investigated in engine studies [37, 38]. A couple of studies [39, 40] have been conducted to suggest surrogate formulations and chemical kinetic modelling of fuels containing ethanol.

The objectives of this study are twofold. First, we aim to investigate the autoignition characteristics of two oxygenated gasoline fuels over a wide range of pressure (10 - 40 bar), temperatures $(650-1250 \mathrm{~K})$ and equivalence ratios in a shock tube and a rapid compression machine. Second, we compare the ignition delay times of gasolines with ternary, quaternary and multi-component surrogates to suggest suitable surrogates for ethanol-containing gasolines. A chemical kinetic model is developed to simulate ignition delay times of the multi-component surrogate and to assess the fidelity of the surrogate model in capturing the auto-ignition behavior of gasoline.

\section{Methodology}

\subsection{Shock Tube}

All measurements were made in a stainless steel shock tube of $63.5 \mathrm{~mm}$ inner diameter with a driver section $3 \mathrm{~m}$ in length, as described in detail previously [38]. The driver and driven sections of the shock tube are separated by a diaphragm chamber which houses two aluminum diaphragms, which are scored to a specific depth depending on the desired pressure behind the reflected shock wave. Shock waves are generated on pressure bursting of the diaphragms causing instantaneous heating of the fuel-air mixture contained in the $5.7 \mathrm{~m}$ long driven section. Shock velocities are determined using six piezoelectric pressure sensors (PCB 113A) mounted at $10,150,430,710,1025$ and $2585 \mathrm{~mm}$ from the end-wall of the driven section. An additional 
pressure sensor (Kistler 603B) is mounted directly on the end-flange of the tube to detect the pressure rise due to ignition. The incident shock speed at the end-wall was determined using linear extrapolation of the axial velocity profile and the incident shock speed was applied to calculate the reflected temperature $\left(T_{5}\right)$ and pressure $\left(p_{5}\right)$ behind the reflected shock wave using the equilibrium program Gaseq [39].

Gasoline/air mixtures were prepared in a stainless-steel mixing vessel. A magnetically controlled fan was used to enhance the mixture homogeneity. Mixtures were prepared manometrically using Baratron pressure manometers. To prevent condensation, the mixing vessel, manifold and shock tube were heated to $393 \mathrm{~K}$ with electrical resistance heaters. Typically, mixtures were allowed to homogenize for at least $2 \mathrm{~h}$ prior to experiments. From the estimated uncertainties in the measured shock velocity and the initial temperature, we calculated a total uncertainty for the temperature behind the reflected shock to be approximately $\pm 15 \mathrm{~K}$. The ignition delay time is defined as the time interval between the arrival of the incident shock at the end-wall and the ignition event recorded by an abrupt pressure rise in the end-wall pressure signal, as shown in Fig. 1. The overall uncertainty in measured shock tube ignition delay times is $\sim 20 \%$.

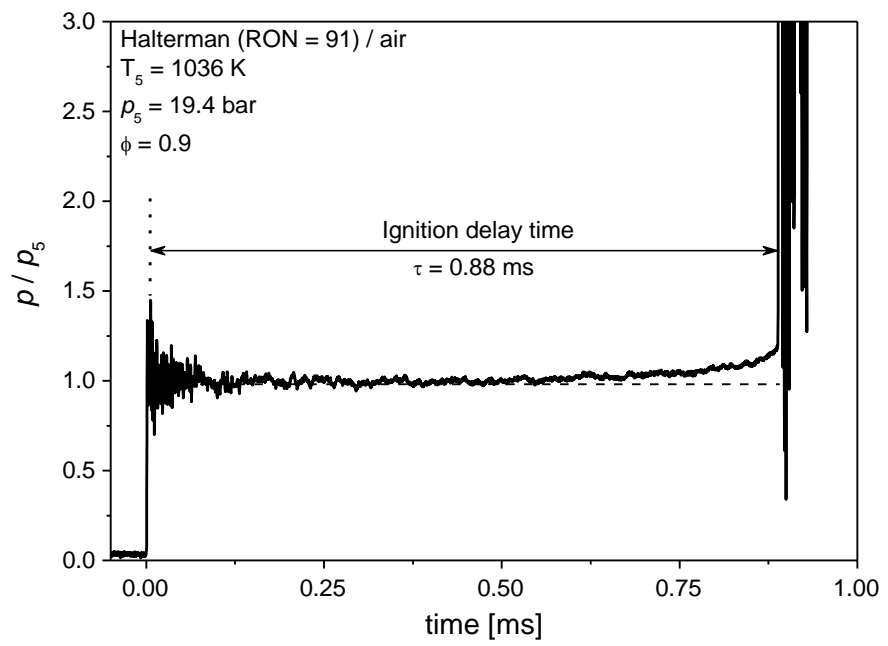

Fig. 1. Example gasoline/air pressure profile showing the definition of ignition delay time for shock tube experiments.

\subsection{Rapid Compression Machine (RCM)}

The ignition delay times at intermediate and low temperature were measured using a rapid compression machine (RCM) facility, which has been described in detail in earlier publications [40-44]. The NUIG RCM is pneumatically driven and hydraulically controlled, and compression times are relatively short at $\sim 16 \mathrm{~ms}$ compared to $>20 \mathrm{~ms}$ in single piston RCM facilities $[45,46]$. The short compression time results from simultaneous movement of the twin opposed pistons. Creviced piston heads were used in this study to suppress the formation of rollup vortex [47]. The initial temperatures and pressures and diluent compositions $\left(\mathrm{N}_{2}, \mathrm{Ar}\right.$ and $\mathrm{CO}_{2}$ ) were adjusted to vary the compressed temperature of the gas mixture at a nominal compressed pressure. To avoid condensation of the two gasoline fuels (Haltermann and Coryton), which have saturation vapor pressures of $49.64 \mathrm{kPa}$ and $59.80 \mathrm{kPa}$ respectively at $310 \mathrm{~K}$, the reaction chamber was wrapped in double-stranded heating tape (Flexelec, $1250 \mathrm{~W}$ ) 
and insulated using a single layer of insulation tape (Zetex 1000). Additionally, six cartridge heaters (hotrod R Type HHP $6.5 \mathrm{~mm}$ ) were inserted into the sleeve wall around the piston head at the start of the compression for a homogenous temperature near the piston heads. Sufficient time was allowed to elapse for the temperature to stabilize in the reaction chamber and in the sleeves at each temperature setting. Initial temperatures of up to $393 \mathrm{~K}$ were studied at a constant geometric compression ratio.

Pressure-time profiles were measured using a dynamic pressure transducer (Kistler 601A) and transferred via an amplifier (Kistler 5018) to the oscilloscope (Picoscope 4424, USB PC oscilloscope) and ultimately recorded digitally on a computer using the Picolog PC software. Ignition delay time was defined as the time difference between the end of compression and the maximum rate of pressure rise due to ignition. Figure 2 illustrates the definition of ignition delay time used in this study, where $d p / d t$ is the time derivative of the pressure trace. The local maximum of $d p / d t$ in the time after compression is defined as the point of ignition. From the experimental pressure trace and the initial experimental conditions, i.e., initial temperature $\left(T_{0}\right)$ and initial pressure $\left(p_{0}\right)$, the compressed gas temperature, $T_{\mathrm{C}}$, was calculated using the following isentropic relation:

$$
\int_{T_{0}}^{T_{c}} \frac{\gamma}{\gamma-1} \frac{d T}{T}=\ln \left[\frac{p_{c}}{p_{0}}\right]
$$

where $p_{\mathrm{C}}$ is the pressure at end-of-compression and $\gamma$ is the ratio of specific heat at constant pressure to specific heat at constant volume. The compressed gas temperatures determined in this manner are then plotted against the measured ignition delay times to obtain overall reactivity profiles of the two gasoline fuels. The uncertainty in the end-of-compression temperature is $<1 \%$ and this primarily comes from uncertainties in pressure measurements and in the $\gamma$ value of the mixture. The overall uncertainty in RCM ignition delay times is $\sim 15 \%$.

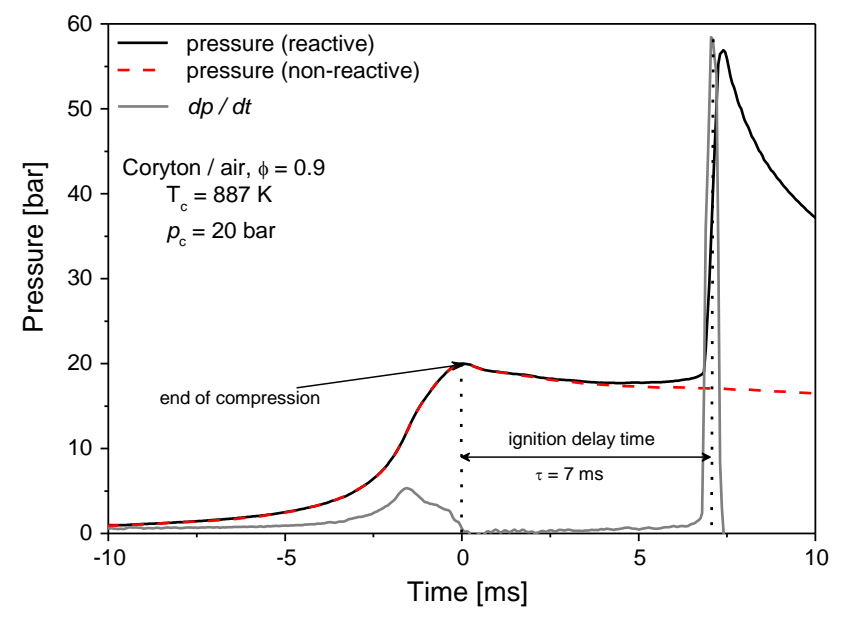

Fig. 2. Representative pressure profile and pressure derivative from rapid compression machine experiments. Definition of ignition delay time is shown. 
Mixtures were prepared in a heated mixing tank. As both gasolines are liquids at room temperature, they were injected into the heated mixing tank using a gas-tight syringe and the partial pressure of fuel was monitored using an MKS pressure transducer. The amount of fuel injected was controlled by measuring the tank pressure. Oxygen and diluent (nitrogen, argon and/or carbon dioxide) were added to the tank to the desired pressure. The molar ratio of oxygen to diluents is 1:3.76 (simulated air). Nitrogen (CP Grade) 99.95\%, argon (Research Grade) 99.9995\%, oxygen (Medical Grade) $99.5 \%$ and carbon dioxide (Research Grade) 99.999\% were all supplied by BOC Ireland and were used without any further purification. The molar compositions of mixtures for both fuels are shown in Table 1. The mixtures were left for at least $2 \mathrm{~h}$ before use to ensure homogeneity. To account for heat loss in RCM ignition experiments, the volume history of the experiments was included in our kinetic simulation [48]. The volume profiles were based on the pressure profiles of non-reactive mixtures, where oxygen was replaced by nitrogen in the corresponding reactive mixture.

Table 1. Composition of the two gasoline mixtures for various equivalence ratios.

\begin{tabular}{cccc}
\hline \multirow{2}{*}{$\varphi$} & \multicolumn{3}{c}{ Mole percentage (\%) } \\
\cline { 2 - 4 } & gasoline & $\mathrm{O}_{2}$ & diluent \\
\hline \multirow{2}{*}{0.45} & 1.020 & Haltermann $(\mathrm{RON}=91)$ & 78.186 \\
0.90 & 2.020 & 20.794 & 77.396 \\
1.80 & 3.959 & 20.584 & 75.864 \\
& & 20.177 & \\
0.45 & & & 78.190 \\
0.90 & 1.015 & 20.795 & 77.404 \\
1.80 & 2.009 & 20.586 & 75.880 \\
\hline
\end{tabular}

\subsection{Fuel Characterization}

The two certification oxygenated gasolines used in this work were supplied by Coryton Advanced Fuels and Haltermann Solutions. The gasoline compositions were determined using detailed hydrocarbon analysis (DHA) at Saudi Aramco's Research and Development Center, following the standard test methods ASTM D6733 and D6730. The vendors' certificate of analysis also provided a distribution of hydrocarbon groups, such as $n$-paraffins, iso-paraffins, olefins, naphthenes, and aromatics (PIONA). A good agreement was observed between the PIONA and DHA results. The DHA methodology was comprehensive in nature and it provided complete isomeric resolution of all species in the gasoline sample. Both the DHA of Coryton and Haltermann resulted into identification of $>99.8 \%$ of species in each gasoline. The complete DHA report is provided as Supplementary Material. Table 2 lists some key properties of the two gasoline fuels. Both Coryton and Haltermann fuels have significant fractions of oxygenates (ethanol), paraffins, iso-paraffins, olefins, naphthenes and aromatics, as shown in Table 2. The main difference between the gasoline fuels used here compared to previous studies is in the oxygenated content; the Coryton and Haltermann gasolines fuels contain 8 mole \% and 17 mole \% ethanol, respectively. On the other hand, the RD 387 used in [1, 49-52] is a research grade gasoline with no oxygenates. 
The DHA was used to calculate the EPIONA (Ethanol + PIONA) distribution, carbon types, $\mathrm{H} / \mathrm{C}$ ratio, and average molecular weight of the Coryton and Haltermann fuels. The RON, MON, density and distillation curves (ASTM D-86) were measured by the suppliers.

Table 2. Key properties and composition of the gasoline fuels. The compositions were calculated using DHA.

\begin{tabular}{|c|c|c|c|c|}
\hline & \multicolumn{2}{|c|}{ Haltermann } & \multicolumn{2}{|c|}{ Coryton } \\
\hline RON & \multicolumn{2}{|c|}{91} & \multicolumn{2}{|c|}{97.5} \\
\hline MON & \multicolumn{2}{|c|}{83.4} & \multicolumn{2}{|c|}{86.6} \\
\hline Sensitivity & \multicolumn{2}{|c|}{7.6} & \multicolumn{2}{|c|}{10.9} \\
\hline \multirow[t]{2}{*}{$\mathrm{H} / \mathrm{C}$ ratio } & \multicolumn{2}{|c|}{1.97} & \multicolumn{2}{|c|}{1.776} \\
\hline & Vol \% & Mol \% & Vol \% & Mol \% \\
\hline oxygenates & 8.2 & 16.8 & 4.0 & 8.2 \\
\hline paraffins & 13.4 & 12.2 & 10.0 & 10.1 \\
\hline iso-paraffins & 33.7 & 26.1 & 38.5 & 31.9 \\
\hline olefins & 6.8 & 6.3 & 10.0 & 11.2 \\
\hline naphthenes & 15.2 & 15.6 & 5.1 & 5.0 \\
\hline aromatics & 22.7 & 22.9 & 32.4 & 33.6 \\
\hline
\end{tabular}

\subsection{Surrogate Formulation}

Surrogate fuels are designed to capture certain target properties of the real fuel; these target properties may be related to the physical and/or chemical behavior of the fuel under investigation. The selection of appropriate target properties is vital to the success of a surrogate. A well-designed surrogate fuel and a well-validated chemical kinetic model facilitate predictive combustion simulations in numerous configurations. Previous surrogates formulation strategies for gasoline fuels have utilized AKI [53], sensitivity [54-56] [20, 26, 39], H/C ratio $[24,57,58][20,24,39]$, PIONA [59, 60] [20,39], RON [50, 51, 61, 62] [22,23,26,39], MON [50, 51, 63, 64] [22,23,26,39], carbon types [65] [24], average molecular weight [65], and distillation curve/volatility $[64,65]$ as target properties. It is noted that targeting properties such as $\mathrm{H} / \mathrm{C}$ ratio and PIONA permit accurate prediction of density and lower heating value (LHV) $[50,65]$.

Primary reference fuel (PRF; mixture of $n$-heptane and iso-octane) is considered to be the simplest surrogate for gasoline fuels. However, a single PRF mixture cannot capture both RON and MON of gasoline because PRFs, by definition, have zero sensitivity. Therefore, for highsensitivity gasolines, like those investigated here, PRF surrogates are not expected to to capture the auto-ignition behavior of gasolines at low and intermediate temperatures [33]. Additionally, a simple surrogate cannot emulate other chemical and physical properties of gasoline. Therefore, in this work, we have investigated three kinds of surrogates for the two gasoline fuels studied here. The surrogate properties and compositions are compared with the gasoline fuels in Table 3 and Fig. 3. 


\section{1) Ternary TPRF (toluene, $n$-heptane, iso-octane) Surrogates}

The TPRF surrogates for the Haltermann and Coryton fuels were formulated based on the correlations developed by Kalghatgi et al. [54]. These correlations calculate the TPRF surrogate composition required to emulate the RON and sensitivity of the target fuel. These surrogates are denoted as HG-TPRF for the Haltermann gasoline (HG) and CG-TPRF for the Coryton gasoline (CG). These surrogates have RON and sensitivity ( $\mathrm{S}=\mathrm{RON}-\mathrm{MON}$ ) equal to those of the Haltermann and Coryton fuels, respectively. Experimental ignition delay times of a variety of TPRF blends, including the two used here, have recently been measured by Javed et al. [52] in shock tube and rapid compression machine over wide range of conditions. Those experimental data as well as kinetic simulations of TPRF surrogates have been used here to compare with the measured ignition delay times of the two certification gasolines of the current work.

\section{2) Quaternary (ethanol, toluene, n-heptane, iso-octane) Surrogates}

As the gasoline fuels used in this study contain ethanol, four-component surrogates consisting of $n$-heptane, iso-octane, toluene and ethanol, are proposed based on the method presented by Anderson et al. [66] for estimating the octane number of alcohol-gasoline blends. These ethanol-containing surrogates are labelled as HG-TPRFE and CG-TPRFE for the Haltermann and Coryton fuels, respectively.

\section{3) Multi-component Surrogates}

The detailed hydrocarbon analyses (DHA) of Coryton and Haltermann fuels were used to select a palette of species for multi-component surrogate formulation. Based on DHA, $n$-butane, $n$ heptane, 2-methylbutane, 2,2,4-trimethylpentane, 1-hexene, cyclopentane, cyclohexane, toluene, 1,2,4-trimethylbenzene and ethanol were selected as surrogate palette species. These species were selected based on their presence in the DHA and also on the availability of detailed kinetic mechanisms.

In addition to RON and MON, several other target properties were identified to formulate multi-component surrogate mixtures. Surrogates with eight species were formulated to match the RON, MON, PIONA, H/C ratio, carbon types, average molecular weight, density, and distillation characteristics for Coryton and Haltermann fuels using the methodology developed previously at KAUST [27]. This approach achieves the optimal surrogate composition by minimizing an objective function representing the difference between the target properties of the real fuel and the corresponding properties of the surrogate mixture. RON and MON of the surrogate mixtures were calculated based on linear by mole blending of the various individual palette compounds. The distillation points and density for surrogate mixtures were calculated using the REFPROP simulation tool coupled to a MATLAB algorithm, as described by Mueller et al. [57]. It is worth noting that the standard distribution of REFPROP does not support property calculations for mixtures comprising pairs of some molecules, namely, $n$ heptane/ethanol, 1,2,4-trimethylbenzene/ethanol and ethanol/1-hexene. For this study, based upon suggestions from Dr. Eric Lemmon at NIST (personal communication), certain approximations have been made to conduct property calculations for such mixtures. Here, $n$ heptane has been approximated as $n$-hexane, 1 -hexene has been approximated as 1-butene and 1,2,4-trimethylbenzene has been approximated as ortho-xylene. These approximations add 
some uncertainty to the properties reported but could not be quantified without an experimental investigation of the interaction parameters between these species. The compositions of surrogates formulated using the KAUST methodology are presented in Table 4. These surrogates are labelled as HG-KAUST and CG-KAUST for Haltermann and Coryton fuels, respectively. The multi-component surrogates are able to adequately capture many properties of the target gasolines, such as RON, MON, H/C ratio, density, average molecular weight, EPIONA, carbon types and distillation curves. Details of these comparisons are provided in the Supplementary Material.

Table 3. Comparison of properties of Haltermann and Coryton fuels and their respective surrogates.

Compositions are given in mole \%.

\begin{tabular}{c|cccc|cccc}
\hline & $\begin{array}{c}\text { Haltermann } \\
\text { (HG) }\end{array}$ & $\begin{array}{c}\text { HG- } \\
\text { TPRF }\end{array}$ & $\begin{array}{c}\text { HG- } \\
\text { TPRFE }\end{array}$ & $\begin{array}{c}\text { HG- } \\
\text { KAUST }\end{array}$ & $\begin{array}{c}\text { Coryton } \\
(\mathrm{CG})\end{array}$ & $\begin{array}{c}\text { CG- } \\
\text { TPRF }\end{array}$ & $\begin{array}{c}\text { CG- } \\
\text { TPRFE }\end{array}$ & $\begin{array}{c}\text { CG- } \\
\text { KAUST }\end{array}$ \\
\hline RON & 91 & $91^{\mathrm{a}}$ & $91^{\mathrm{a}}$ & $91.5^{\mathrm{a}}$ & 97.5 & $97.5^{\mathrm{a}}$ & $97.5^{\mathrm{a}}$ & $99.2^{\mathrm{a}}$ \\
MON & 83.4 & $83.4^{\mathrm{a}}$ & $85.1^{\mathrm{a}}$ & $82.8^{\mathrm{a}}$ & 86.6 & $86.6^{\mathrm{a}}$ & $89.8^{\mathrm{a}}$ & $89.9^{\mathrm{a}}$ \\
sensitivity & 7.6 & 7.6 & 5.9 & 8.7 & 10.9 & 10.9 & 7.7 & 9.3 \\
density $\left(\mathrm{kg} / \mathrm{m}^{3}\right)$ & 755 & 742 & 756 & 739 & 749 & 828 & 770 & 743 \\
H/C & 1.97 & 1.96 & 1.97 & 1.94 & 1.776 & 1.41 & 1.83 & 1.83 \\
avg. mol. wt & 88.8 & 105.4 & 93.9 & 85.3 & 90.6 & 95.1 & 98.0 & 86.9 \\
& & & & & & & & \\
$n$-alkanes & 12.2 & 17.0 & 14.4 & 16.3 & 10.1 & 14.3 & 10.3 & 10.4 \\
iso-alkanes & 26.1 & 54.0 & 40.3 & 22.5 & 31.9 & 8.1 & 41.0 & 29.2 \\
aromatics & 22.9 & 29.0 & 27.3 & 24.2 & 33.6 & 77.6 & 39.9 & 34.3 \\
oxygenates & 16.8 & & 18.0 & 14.7 & 8.2 & & 8.8 & 9.3 \\
alkenes & 6.4 & & & 6.9 & 11.2 & & & 12.5 \\
cycloalkanes & 15.6 & & & 15.4 & 5.0 & & & 4.3 \\
\hline
\end{tabular}

a) Calculated value

Table 3. Composition of the multi-component surrogate mixtures, in mole fractions.

\begin{tabular}{lcc}
\hline \multicolumn{1}{c}{ Palette compound } & HG-KAUST & CG-KAUST \\
\hline$n$-Butane & 0.0715 & 0.0727 \\
2-Methyl butane & 0.1382 & 0.0865 \\
Ethanol & 0.1469 & 0.0934 \\
Cyclopentane & 0.1540 & 0.0000 \\
1,2,4-Trimethylbenzene & 0.2418 & 0.0000 \\
1-Hexene & 0.0691 & 0.1246 \\
$n$-Heptane & 0.0912 & 0.0311 \\
2,2,4-Trimethylpentane & 0.0873 & 0.2061 \\
Toluene & 0.0000 & 0.3426 \\
cyclohexane & 0.0000 & 0.0430 \\
\hline
\end{tabular}



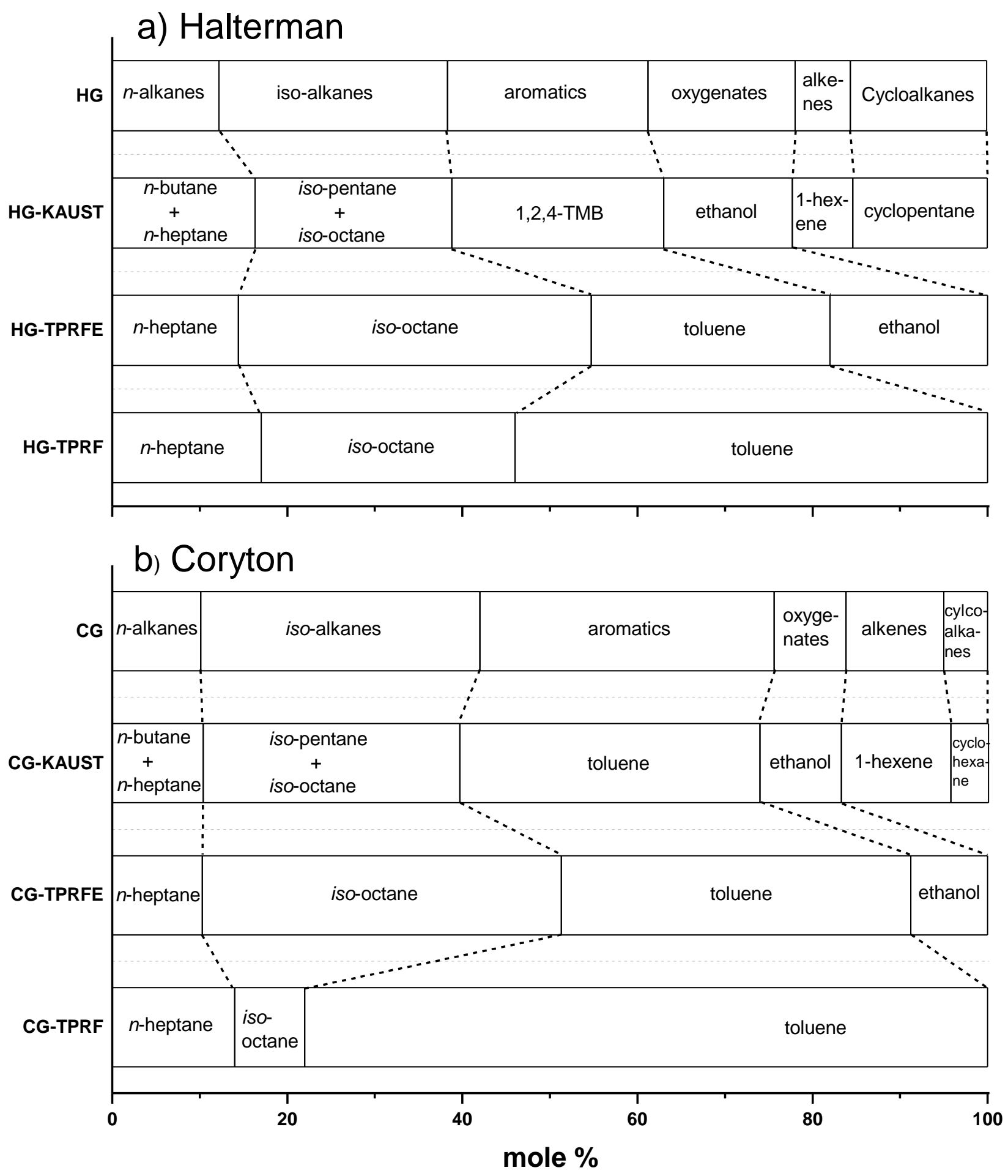

Figure 3. Comparison of the composition of gasoline fuels and their surrogates. 


\section{Results and Discussion}

\subsection{Ignition Delay Time Measurements}

Ignition delay times of Haltermann and Coryton fuels were measured in a shock tube and in a rapid compression machine over a wide range of temperatures $650-1250 \mathrm{~K}$, at pressures in the range $10-40$ bar and at equivalence ratios of $\varphi=0.45,0.9$ and 1.8. All measured ignition delay data are provided in tabular form in the Supplementary Material. Figure 4 shows typical pressure profiles measured in the shock tube; normalized to the pressure behind the reflected shock, $p_{5}$. The pressure profiles depict the expected strong ignition at these high to intermediate temperatures.

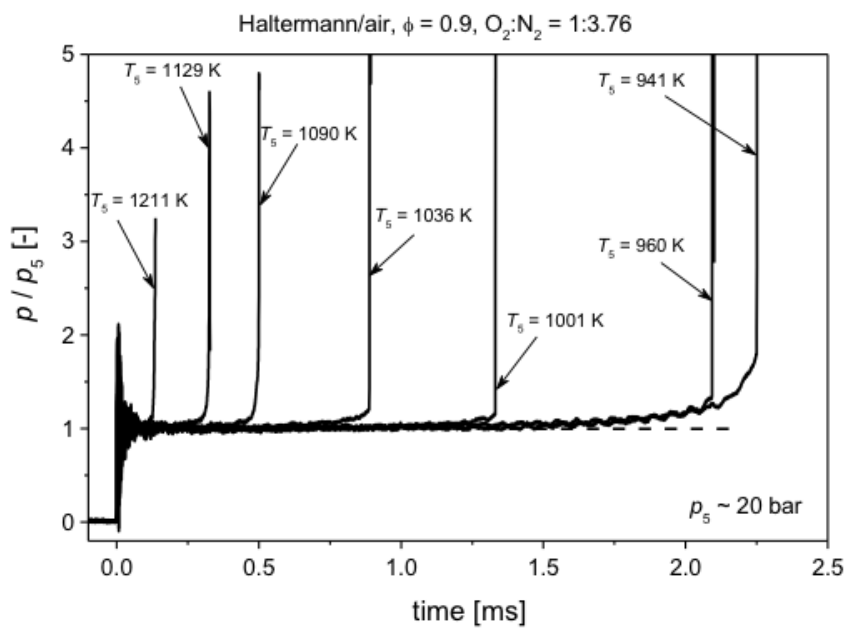

Fig. 4. Normalized shock tube pressure profiles for stoichiometric Haltermann/air mixture at nominal pressure of 20 bar.

Due to the interaction of the reflected shock wave with the boundary layer, a pressure gradient is observed in all experiments resulting in an average $d p / d t \approx 2.5 \sim 3.0 \% / \mathrm{ms}$. This pressure increase is converted into a volume profile and used in ignition delay simulations. Representative pressure traces measured in the RCM are shown in Fig. 5.
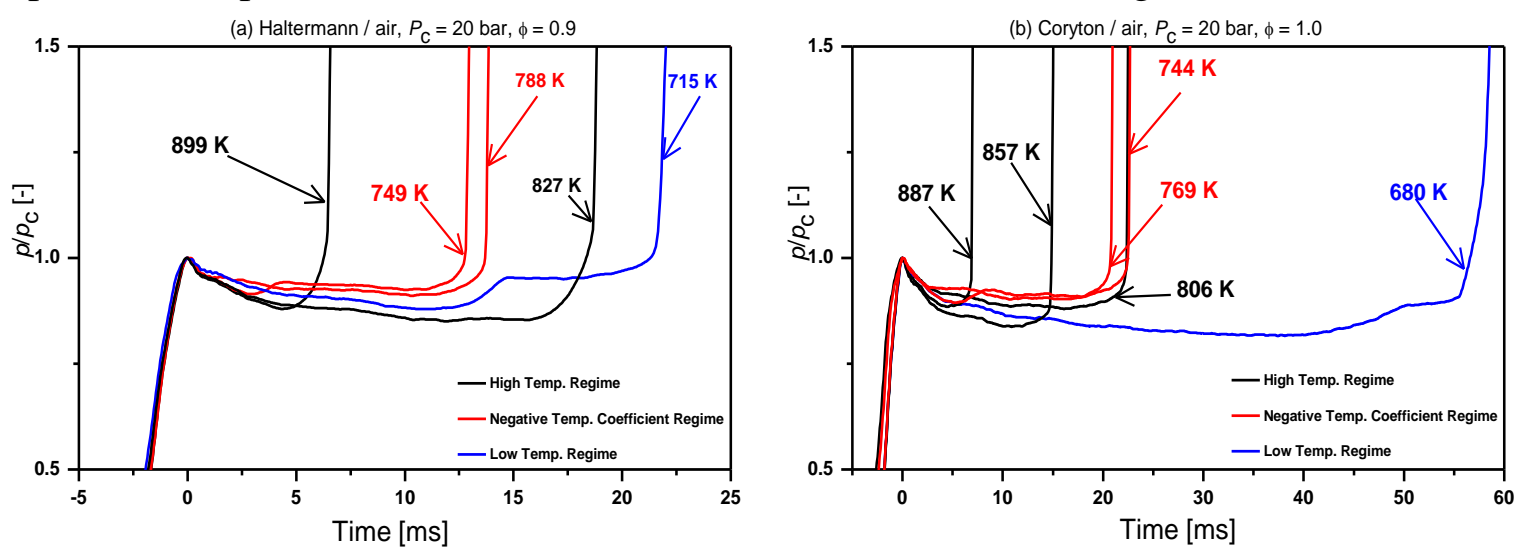

Fig. 5. Experimental RCM pressure traces obtained at 20 bar, $\varphi=0.9$ for (a) Haltermann, (b) Coryton.

The RCM pressure profiles indicate the presence of two-stage ignition and a negative temperature coefficient (NTC) region. The two-stage ignition and NTC behavior are more pronounced for the Haltermann gasoline compared to the Coryton gasoline. This can be traced 
to the lower sensitivity (RON - MON) and larger fraction of paraffins and naphthenes in the Haltermann gasoline. Ignition delay time data for the Coryton $(\mathrm{RON}=97.5)$ and Haltermann ( $\mathrm{RON}=91$ ) fuels are presented as a function of pressure in Fig. 6. It is observed that the mixtures are more reactive at higher pressures than at lower pressures as expected, due to the relative increase in concentration. The NTC region is more pronounced at 10 and 20 bar compared to the 40 bar data. The effect of pressure is greatest in the NTC region and this effect decreases at higher and lower temperatures. Figure 6 also shows that the onset of NTC region moves to higher temperatures as pressure increases. This phenomenon has been observed in several previous studies on hydrocarbon oxidation and is related to the competition between hydrogen peroxide decomposition and the low-temperature chain propagation/termination routes. [58, 59].

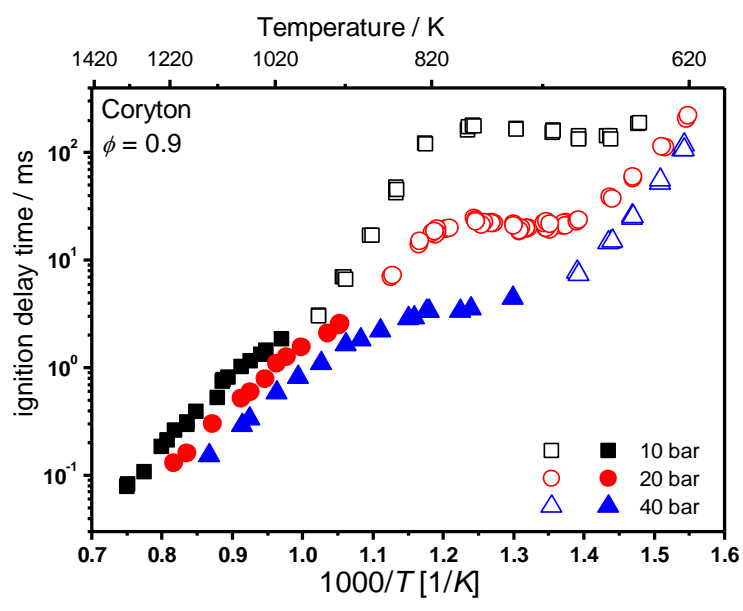

(a)

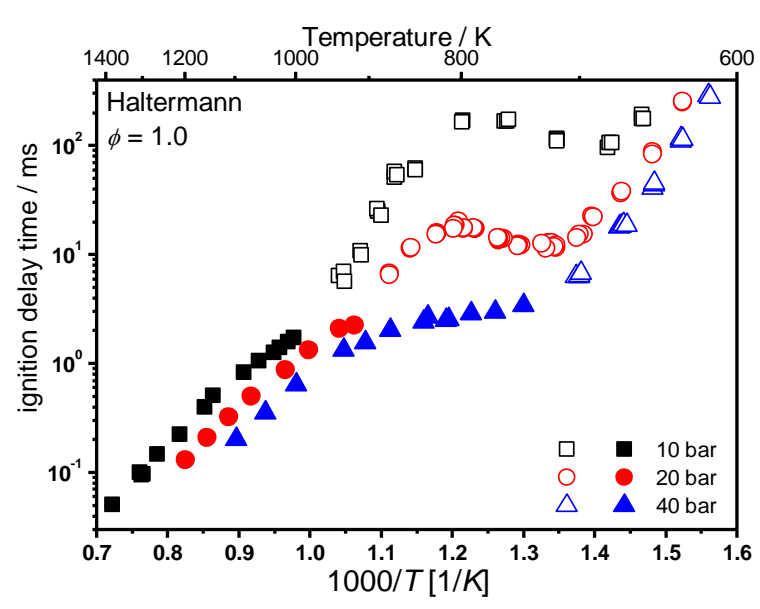

(b)

Fig. 6. Influence of pressure on ignition delay times of (a) Coryton and (b) Haltermann, $\varphi=0.9$ in air. Filled symbols: shock tube, Open symbols: RCM.

Figure 7 shows the effect of equivalence ratio on the ignition delay times of Coryton and Haltermann fuels. In general, fuel-rich mixtures are more reactive than fuel-lean mixtures. Similar to the pressure effect, the dependence of ignition delay times on equivalence ratio is strongest in the NTC region with a negligible dependence on equivalence ratio at high and low temperatures. These observed trends are consistent with previous ignition delay time studies on non-oxygenated gasoline fuels. 


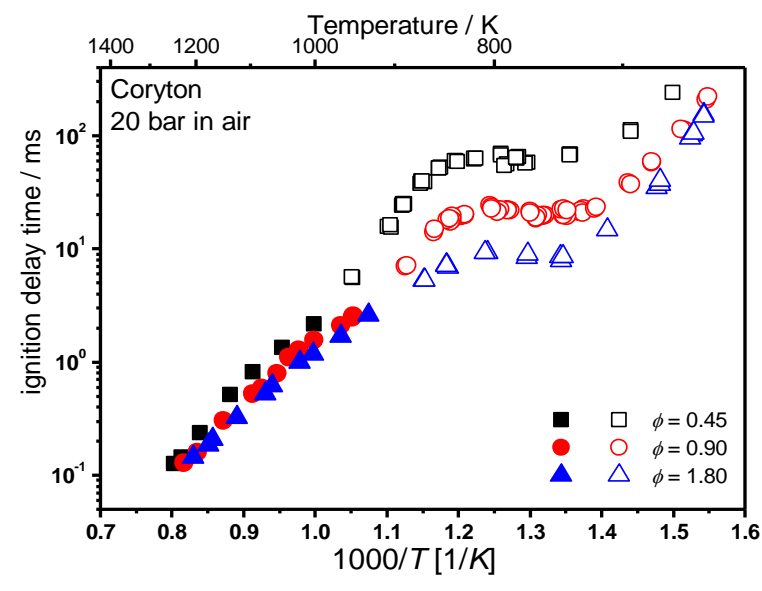

(a)

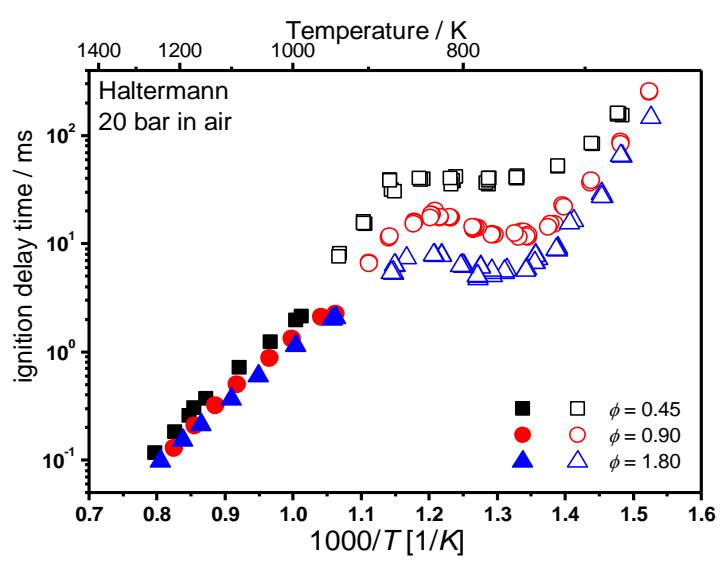

(b)

Fig. 7. Influence of equivalence ratio on ignition delay times of (a) Coryton and (b) Haltermann at 20 bar. Filled symbols: shock tube, Open symbols: RCM.

A key objective of the current work is to understand how the ignition delay times of the two gasoline fuels depend on the composition and the RON/MON. Figure 8 compares the reactivity of Haltermann ( $\mathrm{RON}=91, \mathrm{~S}=7.6)$ and Coryton $(\mathrm{RON}=97.5, \mathrm{~S}=10.9)$ gasolines at various pressures and equivalence ratios. At high temperatures (>900 K), both fuels exhibit very similar reactivity across the range of conditions. However, at intermediate temperatures $(\sim 700$ - $850 \mathrm{~K}$ ), Coryton (black symbols) depicts longer ignition delay times compared to Haltermann (red symbols). This is consistent with the higher research octane number of Coryton gasoline. The dependence of ignition delay times on the type of fuel appears strongest at 20 bar compared to the 10 and 40 bar data. For example, at 20 bar and $\varphi=0.9$, the ignition delay times of the two gasolines differ by almost a factor of two near $770 \mathrm{~K}$. At low temperatures $(<700 \mathrm{~K})$, Haltermann gasoline is slightly less reactive than Coryton gasoline. Secondly, Haltermann gasoline exhibits more pronounced NTC behavior compared to Coryton gasoline. These two observations can be traced to the lower sensitivity of Haltermann gasoline which results in stronger NTC behavior and reduced reactivity (longer ignition delays) at low temperatures. These observations are consistent with previous experimental and modeling works of Sarathy et al. [36] and Mehl et al. [60].
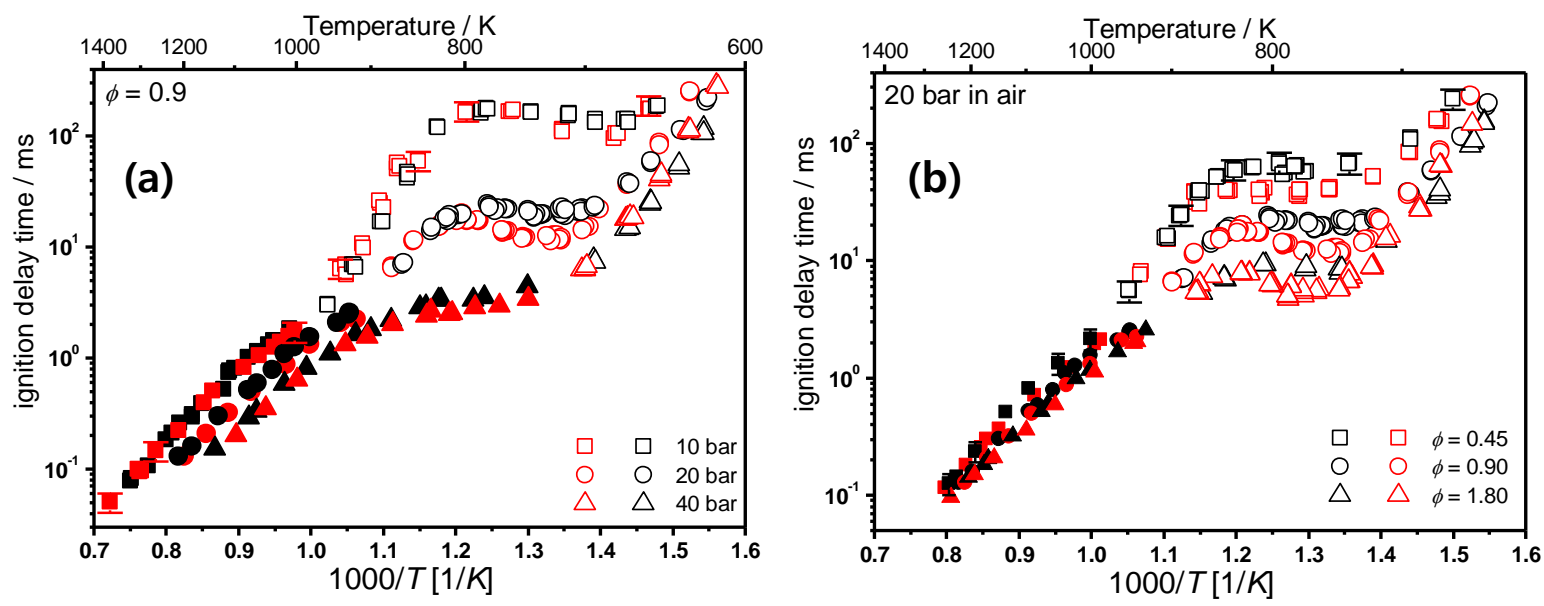
Fig. 8. Comparison of RCM ignition delay data for Coryton (black) and Haltermann (red) at (a) 10, 20, and 40 bar, (b) at $\varphi=0.45,0.9$ and 1.8. Filled symbols: shock tube, Open symbols: RCM. Error bars (15\% for RCM, $20 \%$ for shock tube) are shown on some data points.

\subsection{Comparison of Gasoline Reactivity with Surrogates}

As described in Section 2.4, three surrogates were formulated for both Haltermann and Coryton fuels. The performance of various surrogates is analyzed in detail with the help of chemical kinetic simulations. Additionally, the surrogates for Haltermann gasoline were compared experimentally by measuring ignition delay times in the RCM at nominal pressure of 20 bar and near-stoichiometric; the results are plotted in Fig. 9. The experimental scatter points show that all surrogates display similar ignition delay times and tend to capture the gasoline's ignition behaviour at temperatures of between 700 and $900 \mathrm{~K}$. At temperatures below $700 \mathrm{~K}$, the 4-component surrogate (HG-TPRFE, blue triangle) matches the data more closely compared to the other two surrogates. At temperatures above $850 \mathrm{~K}$ however, the HG-TPRFE surrogate appears to be slower (longer ignition delay times) than the gasoline. At low temperatures $(<750 \mathrm{~K})$, the HG-TPRFE surrogate is the most reactive followed by the HGTPRFE surrogate and then the HG-KAUST surrogate. High paraffinic content in the HG-TPRF mixture leads to faster low-temperature reactions, while a large fraction of aromatics $(1,2,4-$ TMB), in addition to cycloalkane (cyclopentane) and olefins, in the HG-KAUST surrogate leads to relatively slow reactivity at low temperatures.

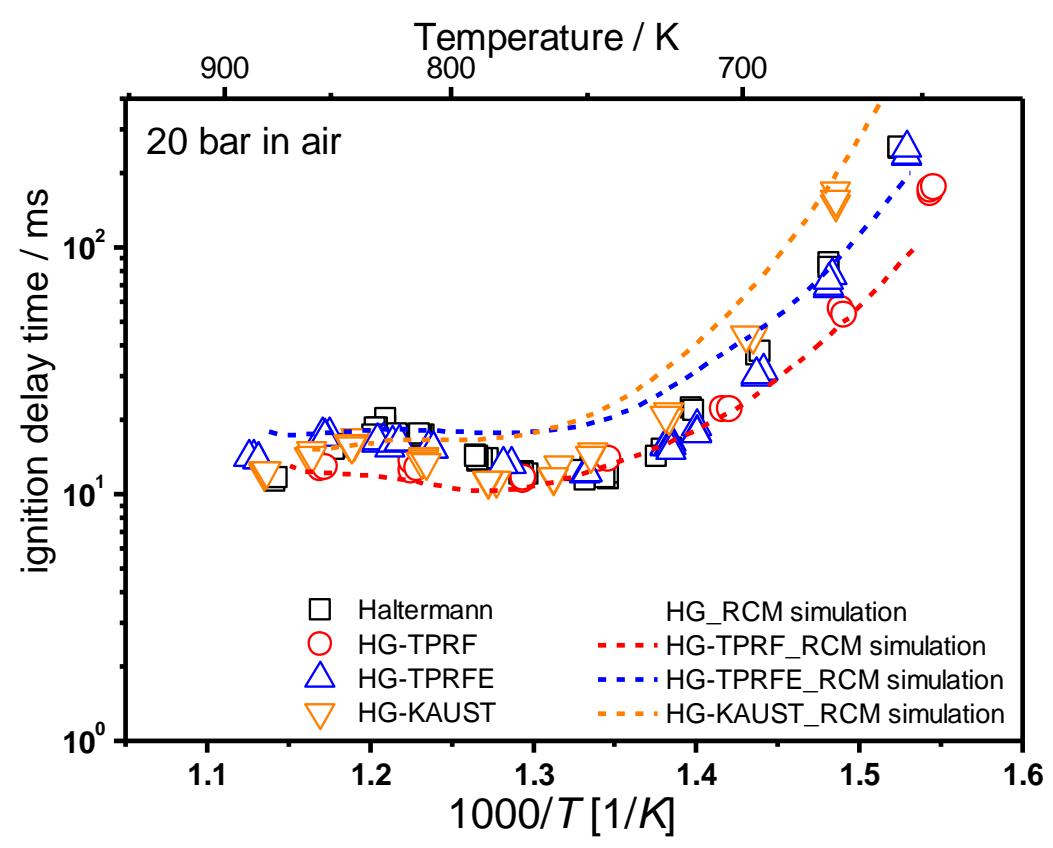

Fig. 9. Comparison of the experimental ignition delay results for Haltermann gasoline and its surrogates at $p_{C}=20$ bar. Equivalence ratio is $\varphi=0.9$ for Haltermann gasoline and $\varphi=0.9$ for the surrogates. For the details of the surrogates, refer to Table 3 . The dashed lines are chemical kinetic simulations using the gasoline surrogate model [35].

The reactivity of the surrogates was simulated using the KAUST-LLNL-NUIG gasoline surrogate model [35] and the resulting predictions are plotted in Fig. 9 (dashed lines). These simulations were performed in Chemkin-Pro [61] with imposed volume profiles which are 
calculated using the non-reactive pressure time-histories measured in RCM experiments where $\mathrm{O}_{2}$ is replaced with $\mathrm{N}_{2}$. The imposition of the volume profiles allows for the effect of pressure drop due to heat loss during the RCM experiments [67]. Several observations can be made from the simulations shown in Fig. 9. The HG-TPRF simulations predict the HG-TPRF experimental data quite well, which indicates that the $n$-heptane, iso-octane and toluene chemistries are adequately modelled in the gasoline surrogate model [35], at least at these specific conditions. The HG-TPRFE simulations predict the HG-TPRFE experimental data reasonably well at high and low temperatures but over-predict the data at intermediate temperatures of $700-800 \mathrm{~K}$. This discrepancy may perhaps be attributed to the deficiency in the ethanol chemistry or the cross-reactivity of ethanol with $n$-heptane, iso-octane or toluene. Similar intermediate temperature over-prediction is observed by comparing the HG-KAUST simulations and HG-KAUST experimental ignition delays.

In order to compare the performance of the various surrogates in predicting the reactivity of the Haltermann gasoline across a wide range of conditions, the measured gasoline ignition delays are compared with the surrogate simulations in Fig. 10. By examining the comparisons at pressures of 10,20 and 40 bar at an $\varphi=0.9$, we can make several observations. All surrogate predictions are almost identical in the high-temperature region (>900 K). For the 40 bar case, we see that the HG-TPRF surrogate better predicts the intermediate-temperature $(750-850 \mathrm{~K})$ shock tube ignition delay data. However, as noted earlier, this surrogate is too reactive at low temperatures $(<700 \mathrm{~K})$. For these low-temperature RCM ignition data, the HG-TPRFE surrogate appears to perform the best while the HG-KAUST surrogate is somewhat slower for the 20 and 40 bar cases. The comparisons at $\varphi=0.45$ and 1.8 show that the HG-TPRF surrogate captures well the variation of gasoline reactivity with equivalence ratio, whereas other surrogates exhibit a slower reactivity compared to the experimental data. All of the comparisons indicate that there are minor differences among the predictions of the three surrogates and the simpler 3-component TPRF surrogate may be chosen to represent the reactivity of the Haltermann gasoline across a wide range of pressures and equivalence ratios. 

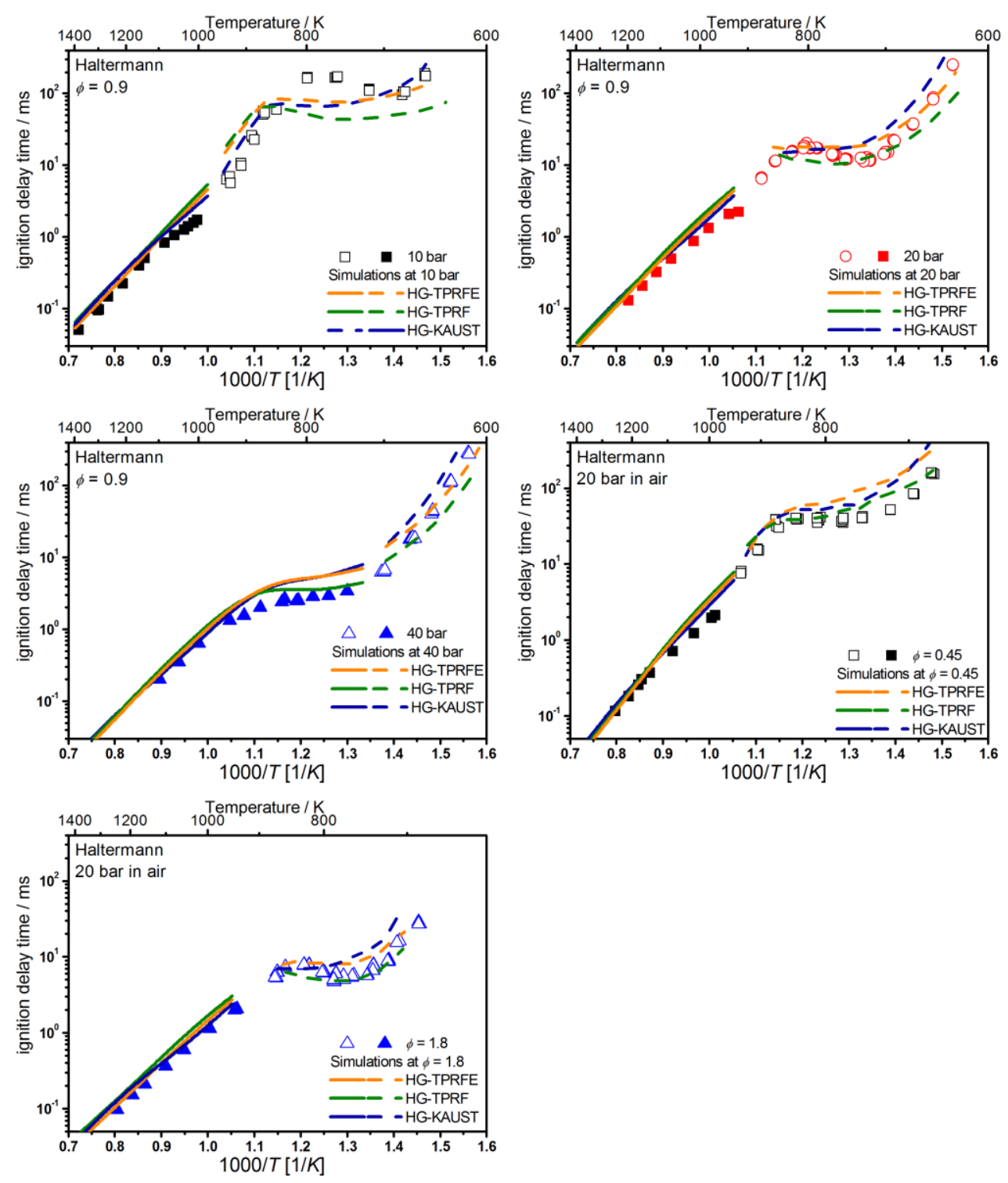

Fig. 10. Comparison of the experimental ignition delay results for the Haltermann gasoline and chemical kinetic simulations of the three surrogates. Solid symbols: shock tube data; Open symbols: RCM data; Solid lines: Constant-volume shock tube simulations; Dashed lines: RCM simulations with imposed volume history of non-reactive traces.

Similarly, to assess the ability of various surrogates in predicting the reactivity of the Coryton gasoline $(\mathrm{RON}=97.5, \mathrm{~S}=10.9)$, the measured gasoline ignition delays are compared with the surrogate simulations in Fig. 11. The high-temperature shock tube ignition delay data show that the CG-TPRF surrogate is too slow compared to the experimental data and compared to the other two surrogates. This is due to the large fraction of toluene ( $77.6 \%$ by mole) in the CG-TPRF surrogate, where toluene is expected to exhibit slow reactivity at these temperatures compared to alkanes. Such a large fraction of toluene was needed in the surrogate to match the relatively high sensitivity (10.9) of the Coryton gasoline. The predicted reactivity of the CGTPRF surrogate is also too slow at intermediate and low temperatures. Comparing the other two surrogates across the range of pressures and equivalence ratios, it can be seen that the CGTPRFE and CG-KAUST have very similar reactivities and reasonably predict the Coryton gasoline ignition data except at 40 bar where the surrogates exhibit a slower reactivity 
compared to the experimental data. It may be argued that the CG-KAUST surrogate shows a marginally better performance compared to the CG-TPRFE surrogate across the range of conditions explored here.

Further comparisons of surrogate simulations and experimental data are provided in the Supplementary Material.
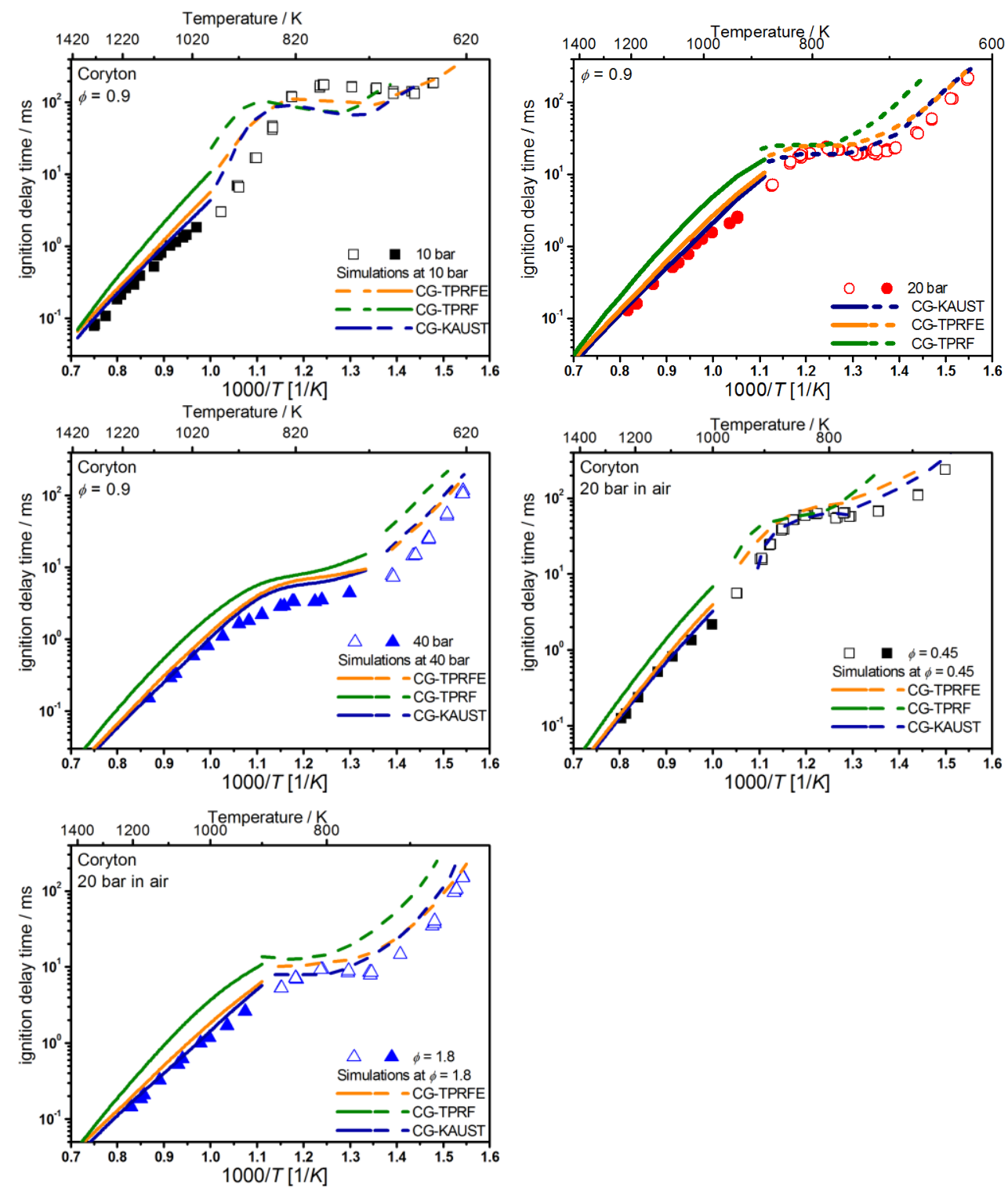

Fig. 11. Comparison of the experimental ignition delay results for Coryton gasoline and chemical kinetic simulations of the three surrogates. Solid symbols: shock tube data; Open symbols: RCM data; Solid lines: Constant-volume shock tube simulations; Dashed lines: RCM simulations with imposed volume history of non-reactive traces. 


\subsection{Chemical Kinetic Analysis}

The previous sections showed several similarities and differences between the experimentally measured ignition characteristics of the Coryton and Haltermann gasoline fuels. First, both fuels display similar ignition delay times in the low-temperature regime below approximately $730 \mathrm{~K}(1000 / T<1.37)$. In the NTC regime $(730-820 \mathrm{~K})$, ignition delay times for the Haltermann gasoline were shorter than those of the Coryton gasoline. The shorter ignition delay times in the NTC regime correlated well with the lower RON and MON values of the Haltermann gasoline compared to the Coryton gasoline.

Simulations with the KAUST-LLNL-NUIG multi-component surrogates were shown to reproduce the experimentally observed trends for both fuels over a wide range of conditions. This section presents simulations and kinetic analysis for the KAUST multi-component surrogates (CG-KAUST and HG-KAUST) in order to provide insights into the effects of gasoline composition on ignition behavior. It should be noted that the simulations with the NUIG surrogates comprising toluene, $n$-heptane, iso-octane, and ethanol provided excellent qualitative and quantitative agreement of the experimental data. However, these were not used for the present analysis because we aim to provide detailed insights into the compositional effects on ignition behavior, for which more complex surrogates offer higher fidelity. The KAUST multi-component surrogates capture the physical and chemical target properties of the gasoline fuels with the highest level of fidelity. The analysis presented herein follows methods previously utilized to study ignition characteristics of non-oxygenated gasoline fuels [25, 35].

Figure 12 presents the simulated constant volume ignition delay times for stoichiometric fuel/air mixtures of CG-KAUST and HG-KAUST surrogates at 20 bar. As observed in the experiments, the surrogate simulations display similar ignition delay times below $715 \mathrm{~K}$ $(1000 / T<1.4)$; despite compositional differences in the two surrogate fuels, their ignition delay times are remarkably similar. Above $715 \mathrm{~K}$, the simulations show a transition into the so-called "NTC regime", albeit a true "negative" slope is not observed. In this region, the ignition delay times for HG-KAUST are approximately $20 \%$ shorter than those of CG-KAUST, which is consistent with the experimental observations for the Haltermann and Coryton fuels.

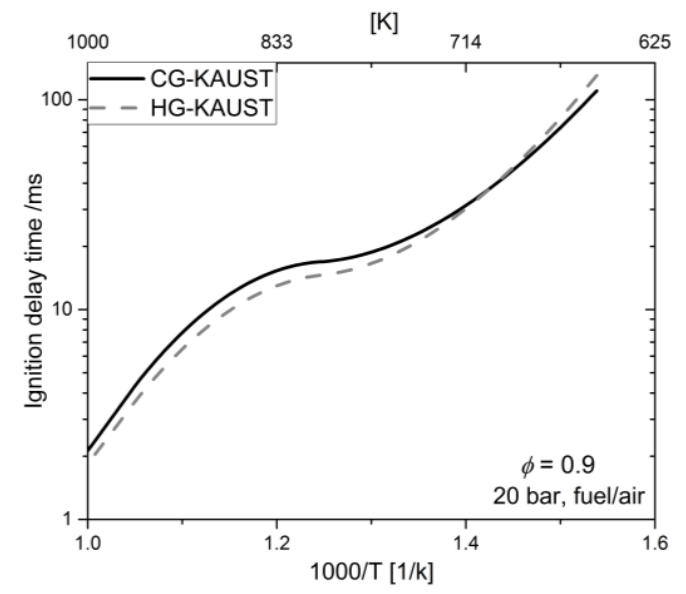

Figure 12. Simulated constant volume ignition delay times for CG-KAUST and HG-KAUST near stoichiometric mixtures with air at 20 bar. 
The global ignition delay time is governed by the evolution of temperature and intermediate radical species during the reactive process. Singh et al. [63] have shown that analysis of temperature and radical species evolution can be utilized to understand the underlying chemical kinetic effects of mixture composition on ignition and octane number. Figure 13 presents the time-histories of temperature, $\dot{\mathrm{O}} \mathrm{H}$ radicals, and $\mathrm{HO}_{2}$ radicals for stoichiometric fuel/air mixtures of CG-KAUST and HG-KAUST mixtures at initial conditions of 20 bar and $700 \mathrm{~K}$ (left) and $800 \mathrm{~K}$ (right). At $700 \mathrm{~K}$, the global ignition delay times of both fuels are similar, but this is achieved by a notably different evolution of temperature and radical species. The CGKAUST surrogate shows an earlier first-stage ignition with low temperature heat release (LTHR) and an earlier rise in $\dot{\mathrm{OH}}$ and $\mathrm{HO}_{2}$ radical concentrations. There is a short delay period before the high temperature heat release (HTHR) or the second-stage ignition event. On the other hand, the HG-KAUST surrogate shows a later first-stage ignition delay time, LTHR, and rise in $\dot{\mathrm{OH}}$ and $\mathrm{HO}_{2}$ radical concentrations, which transitions very quickly to the second-stage ignition. The magnitude of the LTHR and corresponding radical production is greater in CGKAUST than HG-KAUST. The net effect is that both fuels reach global ignition at the same time. At $800 \mathrm{~K}$, the global ignition delay times of both fuels are notably different, with CGKAUST being the less reactive of the two. Ignition at this initial temperature condition does not display typical two-stage characteristics, as there is no clear LTHR or local maximum of $\dot{\mathrm{OH}}$ and $\mathrm{HO}_{2}$ radical concentrations. Instead, ignition appears to be governed by an intermediate temperature heat release (ITHR) [59, 68] event that transitions to HTHR. The radical concentrations in CG-KAUST and HG-KAUST are similar during the initial portion of the reactive process but then deviate around $10 \mathrm{~ms}$; at this point HG-KAUST displays a significant increase in radical production, which results in a shorter global ignition delay time when compared to CG-KAUST.
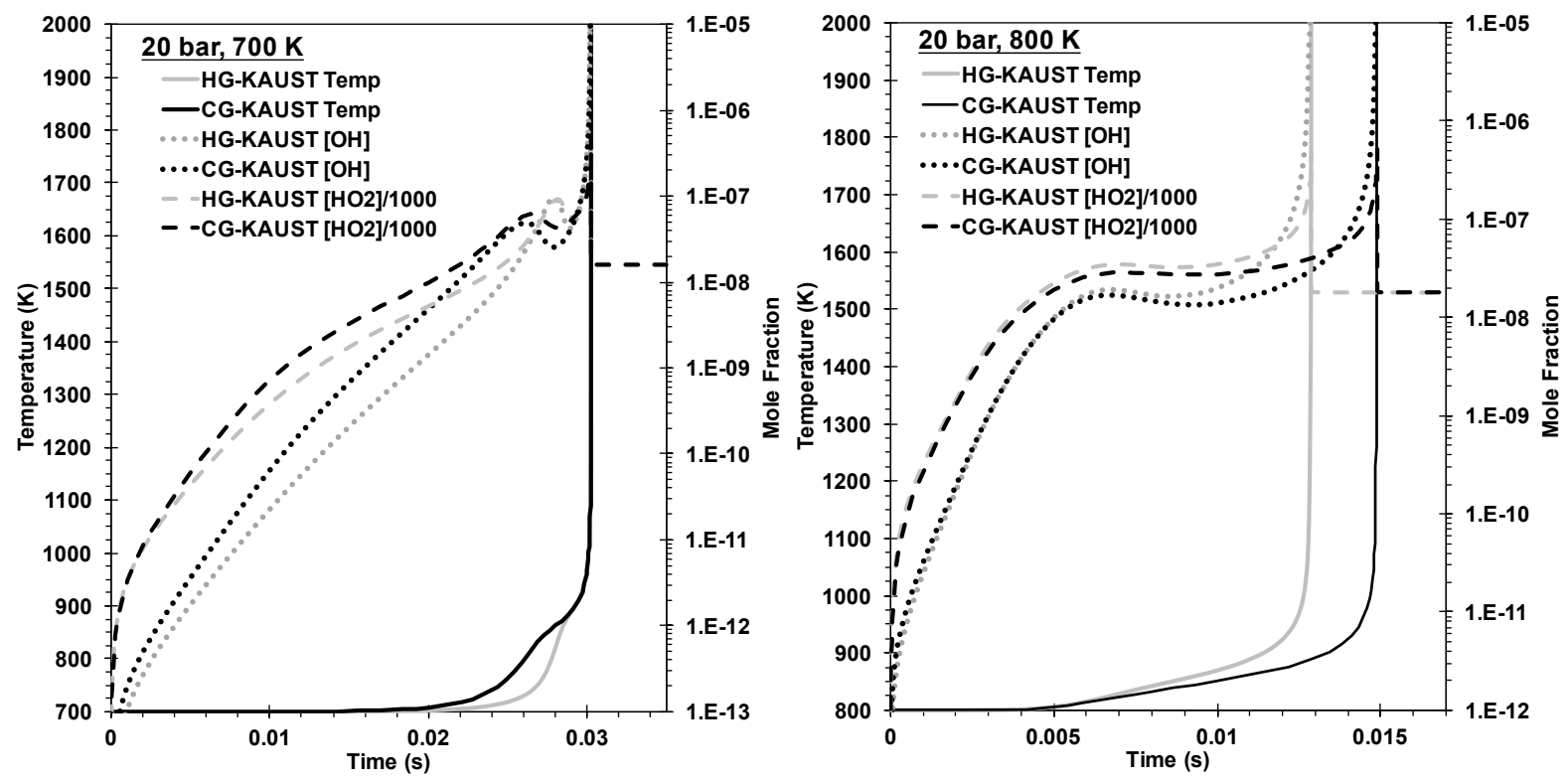

Figure 13: Simulated temperature, $\dot{\mathrm{OH}}$, and $\mathrm{HO}_{2}$ (divided by 1000) time-histories for stoichiometric fuel/air mixtures at $20 \mathrm{bar} 700 \mathrm{~K}$ (left) and $800 \mathrm{~K}$ (right). Arrows mark points of interest (see text). 
The cause of different radical concentrations at $10 \mathrm{~ms}$ was investigated using a rate of production analysis. Figures 14 and 15 present the reactions contributing to the rate of production of OH (left) and $\mathrm{HO}_{2}$ (right) radicals at 20 bar and $800 \mathrm{~K}$ for stoichiometric fuel/air mixtures of CGKAUST and HG-KAUST, respectively. A species dictionary to accompany these figures is included in the Supplementary Material. In both fuels, the decomposition of $\mathrm{H}_{2} \mathrm{O}_{2}$ and $\mathrm{CH}_{3} \mathrm{OOH}$ (i.e., $\mathrm{CH} 3 \mathrm{O} 2 \mathrm{H}$ ) contributes to the production of $\dot{\mathrm{OH}}$ radicals (left panel), but these rates of production are significantly greater in the case of HG-KAUST. It is interesting to note that decomposition of aromatic derived hydroperoxy radicals are key pathways to $\dot{\mathrm{O} H}$ radical production (i.e., benzyl hydroperoxy $[\mathrm{BZCOOH}]$ in CG-KAUST and trimethylbenzyl hydroperoxy [O-XYLCH2OOH and P-XYLCH2OOH] in HG-KAUST). These aromatic derived hydroperoxy radicals originate from the reaction of $\mathrm{HO}_{2}$ radicals with benzylic radicals, as shown previously by Vanhove et al. [69]; the hydroperoxy radical intermediate is unstable and decomposes to form $\dot{\mathrm{OH}}$ and benzoxyl radicals. The source of $\mathrm{HO}_{2}$ radicals is shown in the right panel. Besides the typical $\dot{\mathrm{H}}+\mathrm{O}_{2}$ and $\mathrm{H} \dot{\mathrm{CO}}+\mathrm{O}_{2}$ reactions, $\mathrm{HO}_{2}$ radicals are also produced in significant quantities by the reaction of alpha-hydroxyethyl $(\mathrm{SC} 2 \mathrm{H} 4 \mathrm{OH})$ with $\mathrm{O}_{2}$ to form acetaldehyde $(\mathrm{CH} 3 \mathrm{CHO})$ and $\mathrm{HO}_{2}$ radical. This reaction is the dominant consumption pathway in ethanol oxidation at low and intermediate temperatures, and the cause of its high resistance to autoignition as a pure component [62]. The HG-KAUST surrogate has a larger concentration of ethanol, and, therefore, the aforementioned reaction leads to an increased production of $\mathrm{HO}_{2}$ radicals compared to CG-KAUST. In addition, cyclopentane (CPT) is present in the HG-KAUST surrogate, and $\mathrm{HO}_{2}$ radicals are produced in significant quantities from the concerted elimination of the cyclopentyl peroxy radicals (CPTO2J) [35]. This increased $\mathrm{HO}_{2}$ radical production in the HG-KAUST surrogate leads to an increase in $\mathrm{OH}$ radical production due to the above mentioned aromatic specific reaction pathways. Thus, the presence of ethanol and cyclopentane leads to the production of $\mathrm{HO}_{2}$ radicals and 1,2,4-trimethylbenzene, which subsequently reacts with $\mathrm{HO}_{2}$ radicals producing $\dot{\mathrm{O}} \mathrm{H}$ radicals, and creates a synergy that increases the reactivity of HG-KAUST at $800 \mathrm{~K}$. 

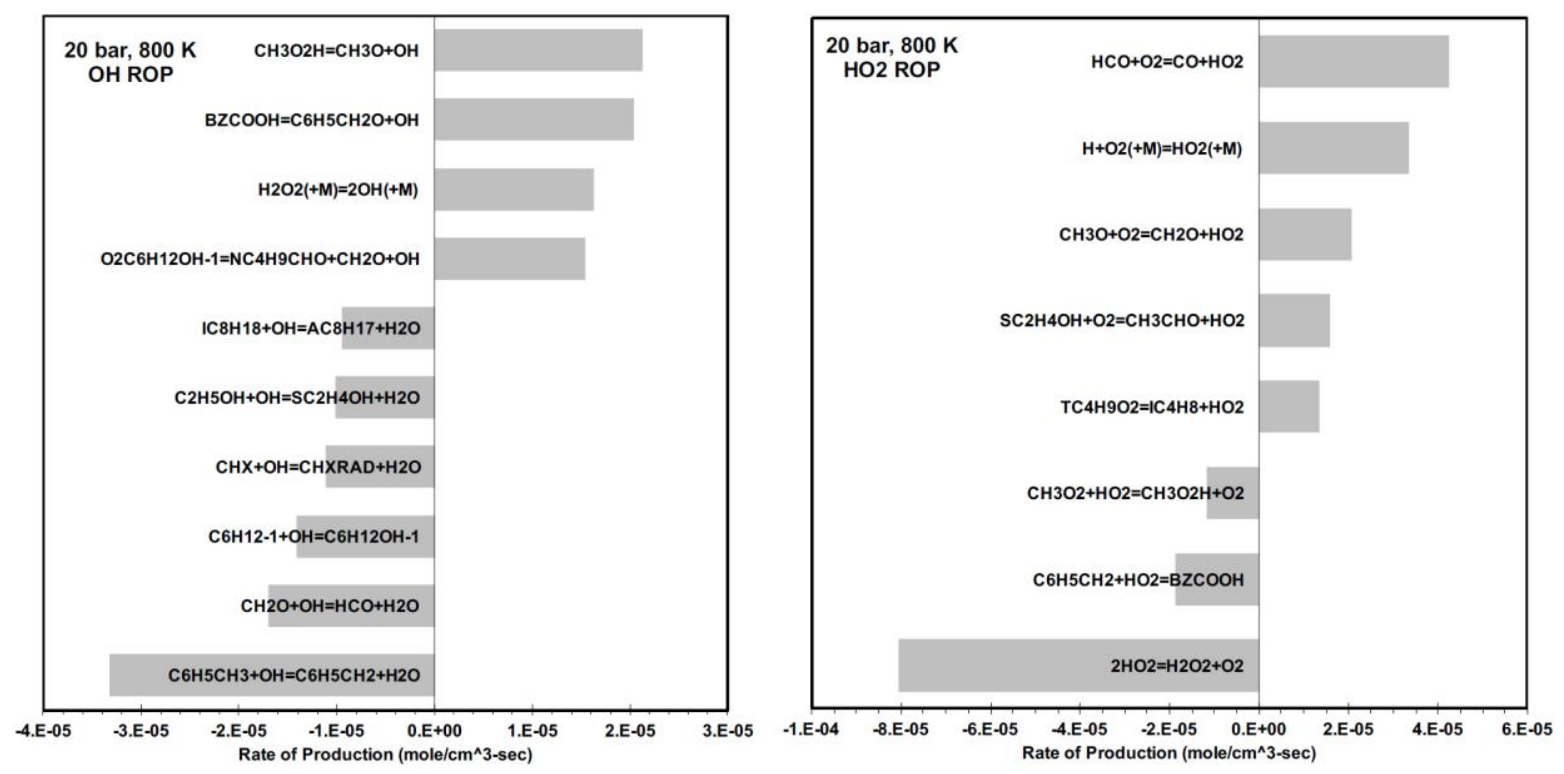

Figure 14: Rate of production of $\dot{\mathrm{O} H}$ (left) and $\mathrm{HO}_{2}$ (right) radicals for CG-KAUST stoichiometric fuel/air mixtures at $20 \mathrm{bar}$ and $800 \mathrm{~K}$. The rate of production is given for the time corresponding to 10 ms.
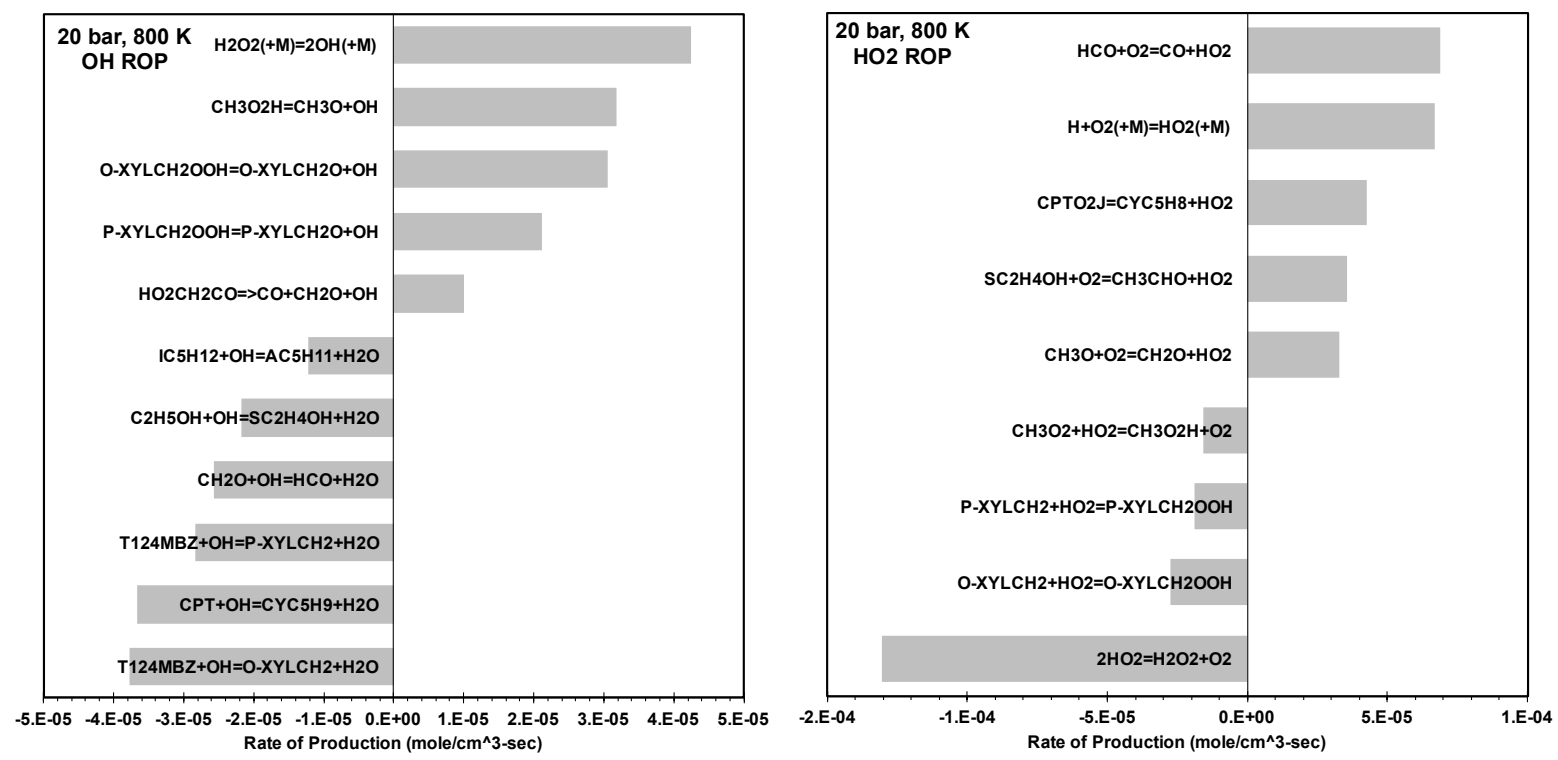

Figure 15: Rate of production of $\mathrm{OH}$ (left) and $\mathrm{HO} 2$ (right) radicals for HG-KAUST stoichiometric fuel/air mixtures at 20 bar and $800 \mathrm{~K}$. The rate of production is given for the time corresponding to 10 ms.

It was previously shown that the simulations using the multi-component surrogate quantitatively over-predicted the ignition delay times of the Haltermann and Coryton fuels at low and intermediate temperatures. A temperature sensitivity analysis at the time of ignition was conducted at $700 \mathrm{~K}$ and $800 \mathrm{~K}$ to identify the reaction rate parameters that are sensitive at these conditions. Figure 16 presents the results at $700 \mathrm{~K}$ while Fig. 17 presents those at $800 \mathrm{~K}$. For the HG-KAUST mixture (left panels), it is clear that increasing the rates of H-atom 
abstraction reactions by $\dot{\mathrm{OH}}$ radicals from 124-TMB, cyclopentane (CPT), and ethanol $(\mathrm{C} 2 \mathrm{H} 5 \mathrm{OH})$ decrease the reactivity of the system because these species do not lead to lowtemperature chain branching. On the other hand, increasing the rates of $\mathrm{H}$-atom abstraction from $n$-heptane $(\mathrm{NC} 7 \mathrm{H} 16)$ and iso-pentane (IC5H12), as well as promoting any $\mathrm{RO}_{2}$ and $\dot{\mathrm{Q} O O H}$ isomerization pathways, would increase the reactivity of the system. The most uncertain reactions are indeed those specific to 124-TMB and cyclopentane (CPT) because these models are newer and less validation data exists; future work should focus more on their ignition chemistry as pure components and in mixtures. In the case of CG-KAUST, H-atom abstraction from toluene $(\mathrm{C} 6 \mathrm{H} 5 \mathrm{CH} 3)$ displays a large negative sensitivity at $700 \mathrm{~K}$ while the reaction of benzyl $(\mathrm{C} 6 \mathrm{H} 5 \mathrm{CH} 2)$ with $\mathrm{HO}_{2}$ radicals to form benzyl hydroperoxide (BZCOOH) shows positive sensitivity at $800 \mathrm{~K}$. Reactions involving cyclohexane (CHX), 1-hexene $(\mathrm{C} 6 \mathrm{H} 12-1)$, and ethanol $(\mathrm{C} 2 \mathrm{H} 5 \mathrm{OH})$ also appear in the sensitivity analysis due to their appreciable content in the CG-KAUST surrogate. A strong relationship is shown between pathways leading to $\dot{\mathrm{O}} \mathrm{H}$ radicals from benzyl radicals $(\mathrm{C} 6 \mathrm{H} 5 \mathrm{CH} 2)$ and the production of $\mathrm{HO}_{2}$ radicals from cyclohexyl peroxy radicals $(\mathrm{CHXO} 2 \mathrm{~J})$. Again, the interplay between $\mathrm{HO}_{2}$ radicals formed from concerted eliminations from cycloalkanes and their subsequent reaction with aromatic benzylic radicals significantly affects the $\dot{O} H$ radical pool in complex fuel mixtures, and this controls ignition. Therefore, further studies need to focus on better modeling of these interactions with simpler binary or ternary mixtures.
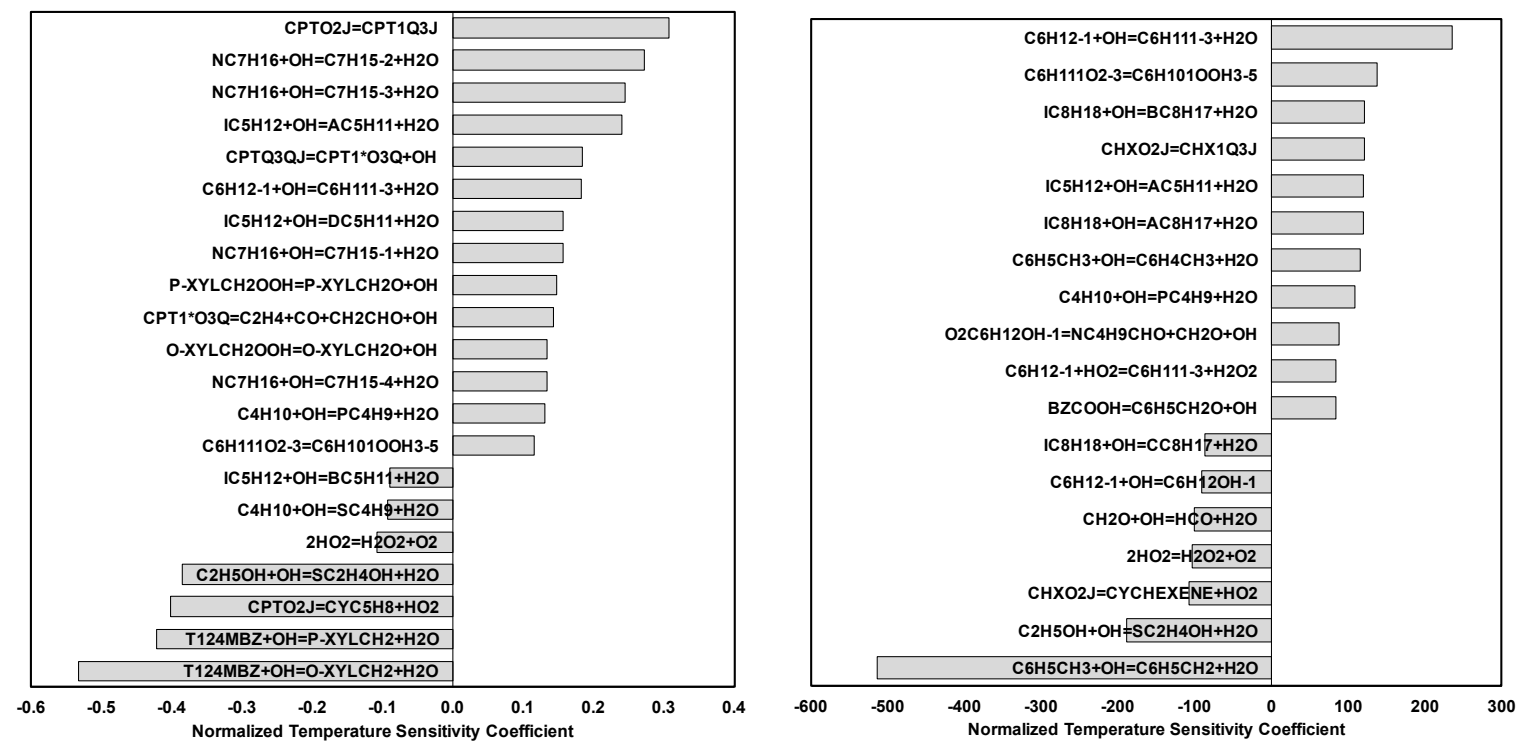

Figure 16: Normalized temperature A-factor sensitivities at the time of ignition for combustion of HGKAUST (left) and CG-KAUST (right) surrogates at $20 \mathrm{~atm}$, stoichiometric fuel/air mixtures, and 700 $\mathrm{K}$. 

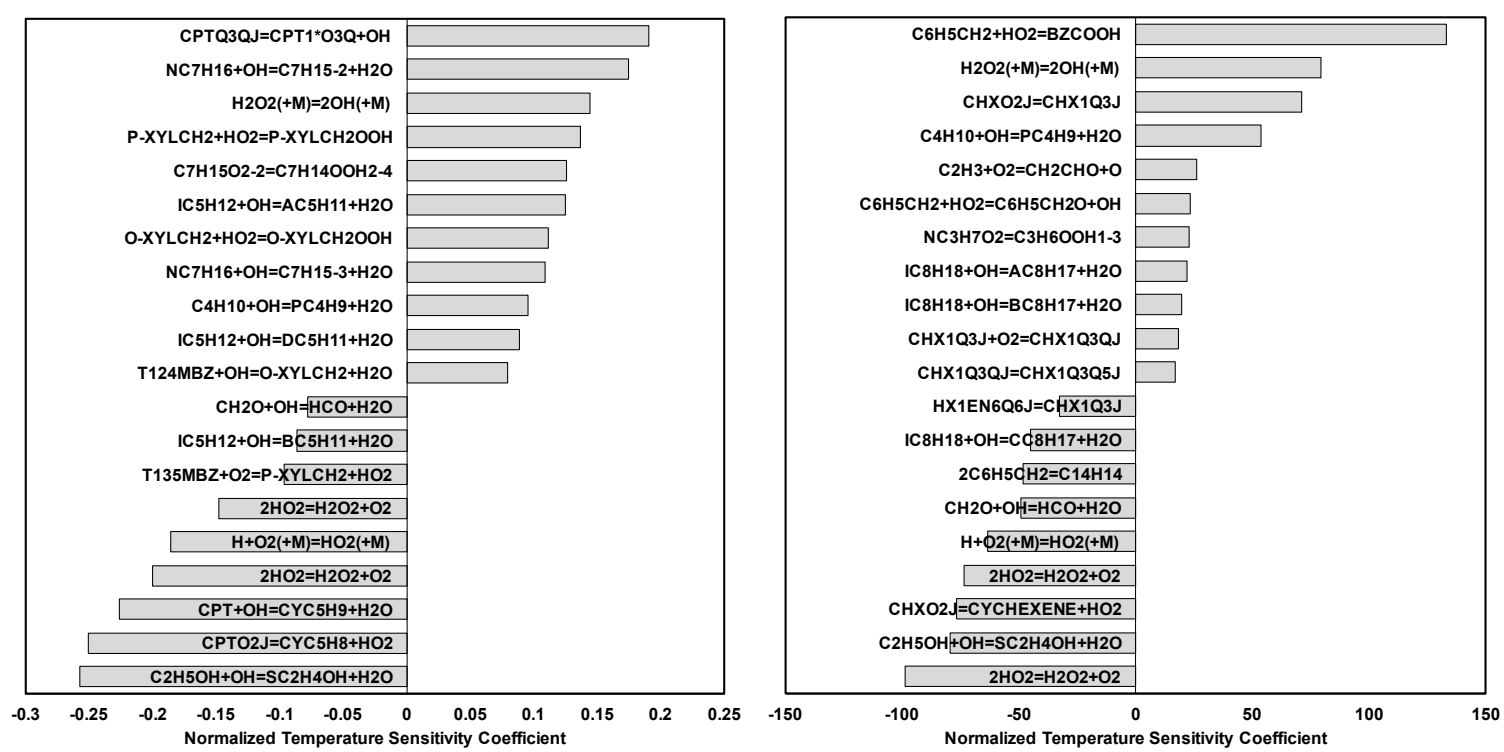

Figure 17: Normalized temperature A-factor sensitivities at the time of ignition for combustion of HG-KAUST (left) and CG-KAUST (right) surrogates at $20 \mathrm{~atm}$, stoichiometric fuel/air mixtures, and $800 \mathrm{~K}$. 


\section{Conclusions}

In this study the autoignition characteristics of two oxygenated gasoline fuels, supplied by Haltermann Solutions and Coryton Advanced Fuels, have been experimentally investigated at a wide range of temperatures, equivalence ratios, and pressures using a rapid compression machine and a high-pressure shock tube. The reactivity of the two gasolines are compared against each other and it is observed that the Coryton gasoline with a higher RON exhibits longer ignition delay times in the NTC region near 700 - $800 \mathrm{~K}$ compared to the Haltermann gasoline which has lower RON. The two gasolines exhibit very similar ignition delay times in the high-temperature (>900 K) region across all pressures and equivalence ratios. In the lowtemperature $(<650 \mathrm{~K})$ region, the Haltermann gasoline is slightly less reactive than the Coryton fuel due to its smaller sensitivity (RON - MON) which also results in more pronounced NTC behavior of the Haltermann gasoline.

Additionally, three surrogates were carefully formulated for each surrogate by matching various fuel characteristics. The simplest surrogate, TPRF (a mixture of $n$-heptane, iso-octane and toluene) is able to adequately capture the reactivity trends of the Haltermann gasoline. However, the four-component surrogate ( $n$-heptane / iso-octane / toluene / ethanol) performs slightly better at low temperatures. For the higher sensitivity Coryton gasoline, the simple TPRF surrogate is too non-reactive due to the very high fraction of toluene which is needed to match the MON requirement of the Coryton gasoline. The four-component and eightcomponent surrogate simulations better reproduce the reactivity of the Coryton gasoline. For either gasoline, one key advantage of the multi-component surrogates is that these are able to better capture a large set of physical and chemical characteristics of the real fuels.

Chemical kinetic analyses performed with the multi-component surrogates illustrate that that the two fuels exhibit similar ignition delay times at high and low temperatures despite having different evolution of temperature and radical species. However, at intermediate temperatures, the Haltermann surrogate exhibits a larger production of $\dot{\mathrm{O}} \mathrm{H}$ radicals from $\dot{\mathrm{O}} \mathrm{H} / \mathrm{HO}_{2}$ kinetic coupling caused by cycloalkanes/aromatics and ethanol/aromatics interactions; this eventually results in shorter ignition delay times of the Haltermann surrogate compared to the Coryton surrogate. The production of $\mathrm{HO}_{2}$ radicals is larger for the Haltermann surrogate due to higher fractions of ethanol and cyclopentane. These compositional effects manifest themselves as difference in autoignition quality, which in turn are important phenomena in developing an understanding of the anti-knock quality of high octane gasoline fuels in modern engines.

\section{Acknowledgements}

Research reported in this paper was funded by Saudi Aramco under the FUELCOM program and by King Abdullah University of Science and Technology (KAUST). 


\section{References}

[1] G. Kalghatgi, Developments in internal combustion engines and implications for combustion science and future transport fuels, Proc. Combust. Inst. 35 (2015) 101 115.

[2] R.D. Reitz, G. Duraisamy, Review of high efficiency and clean reactivity controlled compression ignition ( $\mathrm{RCCl}$ ) combustion in internal combustion engines, Prog. Energy Combust. Sci. 46 (2015) 12-71.

[3] S. Saxena, I.D. Bedoya, Fundamental phenomena affecting low temperature combustion and $\mathrm{HCCl}$ engines, high load limits and strategies for extending these limits, Prog. Energy Combust. Sci. 39 (2013) 457-488.

[4] G.T. Kalghatgi, R.A. Head, The Available and Required Autoignition Quality of Gasoline-Like Fuels in HCCl Engines at High Temperatures, SAE paper 2004-011969 (2004).

[5] W.K. Metcalfe, W.J. Pitz, H.J. Curran, J.M. Simmie, C.K. Westbrook, The development of a detailed chemical kinetic mechanism for diisobutylene and comparison to shock tube ignition times, Proc. Combust. Inst 31 (2007) 377-384.

[6] W.J. Pitz, N.P. Cernansky, F.L. Dryer, F. Egolfopoulos, J. Farrell, D. Friend, H. Pitsch, Development of an experimental database and chemical kinetic models for surrogate gasoline fuels, SAE Technical Paper, 2007.

[7] E. Ranzi, A. Frassoldati, A. Stagni, M. Pelucchi, A. Cuoci, T. Faravelli, Reduced kinetic schemes of complex reaction systems: fossil and biomass-derived transportation fuels, Int. J. Chem. Kinet. 46 (2014) 512-542.

[8] V.S.B. Shankar, M.B. Sajid, K. Al-Qurashi, N. Atef, I. Alkhesho, A. Ahmed, S. Chung, W.L. Roberts, K. Morganti, Primary Reference Fuels (PRFs) as Surrogates for Low Sensitivity Gasoline Fuels, SAE 2016 World Congress and Exhibition, (2016).

[9] J. Badra, A. Elwardany, J. Sim, Y. Viollet, H. Im, J. Chang, Effects of in-cylinder mixing on low octane gasoline compression ignition combustion, SAE Technical Paper, (2016).

[10] J.A. Badra, J. Sim, A. Elwardany, M. Jaasim, Y. Viollet, J. Chang, A. Amer, H.G. Im, Numerical simulations of hollow-cone injection and gasoline compression ignition combustion with naphtha fuels, J. Energy Resources Tech. 138 (2016) 052202. 
[11] M. Chaos, Z. Zhao, A. Kazakov, P. Gokulakrishnan, M. Angioletti, F.L. Dryer, A $\mathrm{PRF}+$ toluene surrogate fuel model for simulating gasoline kinetics, 5th US Combustion Meeting, San Diego, USA, (2007).

[12] H. Machrafi, S. Cavadias, P. Guibert, An experimental and numerical investigation on the influence of external gas recirculation on the $\mathrm{HCCl}$ autoignition process in an engine: Thermal, diluting, and chemical effects, Combust. Flame 155 (2008) 476-489.

[13] A. Yates, A. Bell, A. Swarts, Insights relating to the autoignition characteristics of alcohol fuels, Fuel 89 (2010) 83-93.

[14] D. Bradley, R. Head, Engine autoignition: the relationship between octane numbers and autoignition delay times, Combust. Flame 147 (2006) 171-184.

[15] L. Liang, J.G. Stevens, S. Raman, J.T. Farrell, The use of dynamic adaptive chemistry in combustion simulation of gasoline surrogate fuels, Combust. Flame 156 (2009) 1493-1502.

[16] V. Knop, C. Pera, F. Duffour, Validation of a ternary gasoline surrogate in a CAI engine, Combust. Flame 160 (2013) 2067-2082.

[17] J.C. Andrae, P. Björnbom, R. Cracknell, G.T. Kalghatgi, Autoignition of toluene reference fuels at high pressures modeled with detailed chemical kinetics, Combust. Flame 149 (2007) 2-24.

[18] J.C.G. Andrae, T. Brinck, G.T. Kalghatgi, $\mathrm{HCCl}$ experiments with toluene reference fuels modeled by a semidetailed chemical kinetic model, Combustion and Flame 155 (2008) 696-712.

[19] M. Mehl, G. Vanhove, W.J. Pitz, E. Ranzi, Oxidation and combustion of the nhexene isomers: A wide range kinetic modeling study, Combust. Flame 155 (2008) 756-772.

[20] W.J. Pitz, C. Naik, T.N. Mhaoldúin, C.K. Westbrook, H.J. Curran, J.P. Orme, J. Simmie, Modeling and experimental investigation of methylcyclohexane ignition in a rapid compression machine, Proc. Combust. Inst 31 (2007) 267-275.

[21] P.L. Perez, A.L. Boehman, Experimental investigation of the autoignition behavior of surrogate gasoline fuels in a constant-volume combustion bomb apparatus and its relevance to HCCl combustion, Energy Fuels 26 (2012) 6106-6117. 
[22] M. Mehl, W.J. Pitz, C.K. Westbrook, H.J. Curran, Kinetic modeling of gasoline surrogate components and mixtures under engine conditions, Proc. Combust. Inst 33 (2011) 193-200.

[23] C.V. Naik, W.J. Pitz, C.K. Westbrook, M. Sjöberg, J.E. Dec, J. Orme, H.J. Curran, J.M. Simmie, Detailed chemical kinetic modeling of surrogate fuels for gasoline and application to an HCCl engine, Report No. 0148-7191, SAE Technical Paper, 2005.

[24] E. Singh, J. Badra, M. Mehl, S.M. Sarathy, Chemical Kinetic Insights into the Octane Number and Octane Sensitivity of Gasoline Surrogate Mixtures, Energy Fuels, (2017).

[25] S.M. Sarathy, G. Kukkadapu, M. Mehl, W. Wang, T. Javed, S. Park, M.a. Oehlschlaeger, A. Farooq, W.J. Pitz, C.J. Sung, Ignition of alkane-rich FACE gasoline fuels and their surrogate mixtures, Proceedings of the Combustion Institute 35 (2015) 249-257.

[26] A. Ahmed, G. Goteng, V.S. Shankar, K. Al-Qurashi, W.L. Roberts, S.M. Sarathy, A computational methodology for formulating gasoline surrogate fuels with accurate physical and chemical kinetic properties, Fuel 143 (2015) 290-300.

[27] T.M. Foong, K.J. Morganti, M.J. Brear, G. da Silva, Y. Yang, F.L. Dryer, The octane numbers of ethanol blended with gasoline and its surrogates, Fuel 115 (2014) 727739 .

[28] Renewable energy progress report, Report No. 293 Final, European Commission, Brussels, 2015.

[29] B. Gauthier, D.F. Davidson, R.K. Hanson, Shock tube determination of ignition delay times in full-blend and surrogate fuel mixtures, Combust. Flame 139 (2004) 300-311.

[30] M. Mehl, J.Y. Chen, W.J. Pitz, S.M. Sarathy, C.K. Westbrook, An approach for formulating surrogates for gasoline with application toward a reduced surrogate mechanism for CFD engine modeling, Energy and Fuels 25 (2011) 5215-5223.

[31] H. Wang, M. Yao, Z. Yue, M. Jia, R.D. Reitz, A reduced toluene reference fuel chemical kinetic mechanism for combustion and polycyclic-aromatic hydrocarbon predictions, Combust. Flame 162 (2015) 2390-2404.

[32] B.J. Zhong, D. Zheng, A chemical mechanism for ignition and oxidation of multi-component gasoline surrogate fuels, Fuel 128 (2014) 458-466. 
[33] G. Kukkadapu, K. Kumar, C.-J. Sung, M. Mehl, W.J. Pitz, Experimental and surrogate modeling study of gasoline ignition in a rapid compression machine, Combust. Flame 159 (2012) 3066-3078.

[34] G. Kukkadapu, K. Kumar, C.-J. Sung, M. Mehl, W.J. Pitz, Autoignition of gasoline surrogates at low temperature combustion conditions, Combustion and Flame 162 (2015) 2272-2285.

[35] S.M. Sarathy, G. Kukkadapu, M. Mehl, T. Javed, A. Ahmed, N. Naser, A. Tekawade, G. Kosiba, M. AlAbbad, E. Singh, S. Park, M.A. Rashidi, S.H. Chung, W.L. Roberts, M.A. Oehlschlaeger, C.-J. Sung, A. Farooq, Compositional effects on the ignition of FACE gasolines, Combustion and Flame 169 (2016) 171-193.

[36] A.S. AlRamadan, S.M. Sarathy, M. Khurshid, J. Badra, A blending rule for octane numbers of PRFs and TPRFs with ethanol, Fuel 180 (2016) 175-186.

[37] J.E. Anderson, T.G. Leone, M.H. Shelby, T.J. Wallington, J.J. Bizub, M. Foster, M.G. Lynskey, D. Polovina, Octane numbers of ethanol-gasoline blends: measurements and novel estimation method from molar composition, SAE Technical Paper, (2012).

[38] J.C. Andrae, R. Head, $\mathrm{HCCl}$ experiments with gasoline surrogate fuels modeled by a semidetailed chemical kinetic model, Combust. Flame 156 (2009) 842-851.

[39] L. Cancino, M. Fikri, A. Oliveira, C. Schulz, Ignition delay times of ethanolcontaining multi-component gasoline surrogates: Shock-tube experiments and detailed modeling, Fuel 90 (2011) 1238-1244.

[40] D. Darcy, M. Mehl, J.M. Simmie, J. Würmel, W. Metcalfe, C. Westbrook, W. Pitz, $\mathrm{H}$. Curran, An experimental and modeling study of the shock tube ignition of a mixture of $\mathrm{n}$-heptane and $\mathrm{n}$-propylbenzene as a surrogate for a large alkyl benzene, Proc. Combust. Inst 34 (2013) 411-418.

[41] C. Morley, GasEq, 2004.

[42] L. Brett, J. MacNamara, P. Musch, J. Simmie, Simulation of methane autoignition in a rapid compression machine with creviced pistons, Combust. Flame 124 (2001) 326-329.

[43] D. Darcy, H. Nakamura, C.J. Tobin, M. Mehl, W.K. Metcalfe, W.J. Pitz, C.K. Westbrook, H.J. Curran, An experimental and modeling study of surrogate mixtures of $\mathrm{n}$-propyl-and $\mathrm{n}$-butylbenzene in $\mathrm{n}$-heptane to simulate $\mathrm{n}$-decylbenzene ignition, Combust. Flame 161 (2014) 1460-1473. 
[44] S. Gallagher, H. Curran, W. Metcalfe, D. Healy, J. Simmie, G. Bourque, A rapid compression machine study of the oxidation of propane in the negative temperature coefficient regime, Combust. Flame 153 (2008) 316-333.

[45] H. Nakamura, D. Darcy, M. Mehl, C.J. Tobin, W.K. Metcalfe, W.J. Pitz, C.K. Westbrook, H.J. Curran, An experimental and modeling study of shock tube and rapid compression machine ignition of n-butylbenzene/air mixtures, Combust. Flame 161 (2014) 49-64.

[46] S.M. Sarathy, T. Javed, F. Karsenty, A. Heufer, W. Wang, S. Park, A. Elwardany, A. Farooq, C.K. Westbrook, W.J. Pitz, A comprehensive combustion chemistry study of 2, 5-dimethylhexane, Combust. Flame 161 (2014) 1444-1459.

[47] S. Vranckx, C. Lee, H. Chakravarty, R. Fernandes, A rapid compression machine study of the low temperature combustion of cyclohexane at elevated pressures, Proc. Combust. Inst 34 (2013) 377-384.

[48] G. Mittal, M.P. Raju, C.-J. Sung, CFD modeling of two-stage ignition in a rapid compression machine: Assessment of zero-dimensional approach, Combustion and Flame 157 (2010) 1316-1324.

[49] J.E. Dec, Y. Yang, N. Dronniou, Boosted HCCl-controlling pressure-rise rates for performance improvements using partial fuel stratification with conventional gasoline, SAE Intl. J Engines 4 (2011) 1169-1189.

[50] C. Pera, V. Knop, Methodology to define gasoline surrogates dedicated to auto-ignition in engines, Fuel 96 (2012) 59-69.

[51] K. Puduppakkam, L. Liang, C. Naik, E. Meeks, B.G. Bunting, Combustion and emissions modeling of gasoline $\mathrm{HCCl}$ engine using model fuels, SAE Technical Paper 2009-01-0669 (2009) 1-11.

[52] T. Javed, C. Lee, M. AlAbbad, K. Djebbi, M. Beshir, J. Badra, H. Curran, A. Farooq, Ignition studies of $n$-heptane/iso-octane/toluene blends, Combust. Flame 171 (2016) 223-233.

[53] J. Anderson, U. Kramer, S. Mueller, T. Wallington, Octane numbers of ethanoland methanol- gasoline blends estimated from molar concentrations, Energy Fuels 24 (2010) 6576-6585.

[54] C.J. Mueller, W.J. Cannella, T.J. Bruno, B. Bunting, H.D. Dettman, J.A. Franz, M.L. Huber, M. Natarajan, W.J. Pitz, M.A. Ratcliff, Methodology for formulating diesel 
surrogate fuels with accurate compositional, ignition-quality, and volatility characteristics, Energy Fuels 26 (2012) 3284-3303.

[55] S.S. Merchant, C.F. Goldsmith, A.G. Vandeputte, M.P. Burke, S.J. Klippenstein, W.H. Green, Understanding low-temperature first-stage ignition delay: Propane, Combust. Flame 162 (2015) 3658-3673.

[56] J.C. Prince, F.A. Williams, Short chemical-kinetic mechanisms for lowtemperature ignition of propane and ethane, Combust. Flame 159 (2012) 23362344.

[57] M. Mehl, J.-Y. Chen, W.J. Pitz, S.M. Sarathy, C.K. Westbrook, An approach for formulating surrogates for gasoline with application toward a reduced surrogate mechanism for CFD engine modeling, Energy Fuels 25 (2011) 5215-5223.

[58] CHEMKIN-PRO, Release 15101, Reaction Design, Inc.: San Diego, CA, 2010.

[59] D. Vuilleumier, D. Kozarac, M. Mehl, S. Saxena, W.J. Pitz, R.W. Dibble, J.-Y. Chen, S. Mani Sarathy, Intermediate temperature heat release in an $\mathrm{HCCl}$ engine fueled by ethanol/n-heptane mixtures: An experimental and modeling study, Combustion and Flame 161 (2014) 680-695.

[60] W. Hwang, J. Dec, M. Sjöberg, Spectroscopic and chemical-kinetic analysis of the phases of $\mathrm{HCCl}$ autoignition and combustion for single-and two-stage ignition fuels, Combust. Flame 154 (2008) 387-409.

[61] G. Vanhove, G. Petit, R. Minetti, Experimental study of the kinetic interactions in the low-temperature autoignition of hydrocarbon binary mixtures and a surrogate fuel, Combust. Flame 145 (2006) 521-532.

[62] S.M. Sarathy, P. Osswald, N. Hansen, K. Kohse-Hoeinghaus, Alcohol combustion chemistry, Prog. Energy Combust. Sci. 44 (2014) 40-102.

[63] G.T. Kalghatgi, Developments in internal combustion engines and implications for combustion science and future transport fuels, Proc. Combust. Inst. 35 (2015) 101-115.

[64] C.V. Naik, K. Puduppakkam, C. Wang, J. Kottalam, L. Liang, D. Hodgson, E. Meeks, Applying Detailed Kinetics to Realistic Engine Simulation: the Surrogate Blend Optimizer and Mechanism Reduction Strategies, SAE Int. J. Engines 3 (2010) 241-259. 
[65] A. Ahmed, G. Goteng, V.S.B. Shankar, K. Al-Qurashi, W.L. Roberts, S.M. Sarathy, A computational methodology for formulating gasoline surrogate fuels with accurate physical and chemical kinetic properties, Fuel 143 (2015) 290-300.

[66] J.E. Anderson, U. Kramer, S.A. Mueller, T.J. Wallington, Octane Numbers of Ethanol- and Methanol-Gasoline Blends Estimated from Molar Concentrations, Energy Fuels 24 (2010) 6576-6585.

[67] G. Mittal, M. Chaos, C.-J. Sung, F.L. Dryer, Dimethyl ether autoignition in a rapid compression machine: Experiments and chemical kinetic modeling, Fuel Proc. Technol. 89 (2008) 1244-1254.

[68] W. Hwang, J. Dec, M. Sjöberg, Spectroscopic and chemical-kinetic analysis of the phases of $\mathrm{HCCl}$ autoignition and combustion for single- and two-stage ignition fuels, Combust. Flame 154 (2008) 387-409.

[69] G. Vanhove, G. Petit, R. Minetti, Experimental study of the kinetic interactions in the low-temperature autoignition of hydrocarbon binary mixtures and a surrogate fuel, Combust. Flame 145 (2006) 521-532. 